\title{
Article \\ Restraint upon Embryonic Metatarsal Ex Vivo Growth by Hydrogel Reveals Interaction between Quasi-Static Load and the mTOR Pathway
}

\author{
Soraia Caetano-Silva *(D), Bigboy H. Simbi, Neil Marr $\mathbb{D}^{\mathrm{D}}$, Andrew Hibbert, Steve P. Allen and Andrew A. Pitsillides \\ Comparative Biomedical Sciences Department, Royal Veterinary College, London NW1 0TU, UK; \\ bsimbi@rvc.ac.uk (B.H.S.); nmarr@rvc.ac.uk (N.M.); ahibbert@rvc.ac.uk (A.H.); sallen@rvc.ac.uk (S.P.A.); \\ apitsillides@rvc.ac.uk (A.A.P.) \\ * Correspondence: ssilva7@rvc.ac.uk
}

Citation: Caetano-Silva, S.; Simbi, B.H.; Marr, N.; Hibbert, A.; Allen, S.P.; Pitsillides, A.A. Restraint upon Embryonic Metatarsal Ex Vivo Growth by Hydrogel Reveals Interaction between Quasi-Static Load and the mTOR Pathway. Int. J. Mol. Sci. 2021, 22, 13220. https:// doi.org/10.3390/ijms222413220

Academic Editors: Peter Angele, Denitsa Docheva, Johannes Zellner and Girish Pattappa

Received: 9 November 2021

Accepted: 2 December 2021

Published: 8 December 2021

Publisher's Note: MDPI stays neutral with regard to jurisdictional claims in published maps and institutional affiliations.

Copyright: (c) 2021 by the authors. Licensee MDPI, Basel, Switzerland. This article is an open access article distributed under the terms and conditions of the Creative Commons Attribution (CC BY) license (https:// creativecommons.org/licenses/by/ $4.0 /)$.
Abstract: Mechanical cues play a vital role in limb skeletal development, yet their influence and underpinning mechanisms in the regulation of endochondral ossification (EO) processes are incompletely defined. Furthermore, interactions between endochondral growth and mechanics and the mTOR/NF-kB pathways are yet to be explored. An appreciation of how mechanical cues regulate EO would also clearly be beneficial in the context of fracture healing and bone diseases, where these processes are recapitulated. The study herein addresses the hypothesis that the mTOR/NF-kB pathways interact with mechanics to control endochondral growth. To test this, murine embryonic metatarsals were incubated ex vivo in a hydrogel, allowing for the effects of quasi-static loading on longitudinal growth to be assessed. The results showed significant restriction of metatarsal growth under quasi-static loading during a 14-day period and concentration-dependent sensitivity to hydrogelrelated restriction. This study also showed that hydrogel-treated metatarsals retain their viability and do not present with increased apoptosis. Metatarsals exhibited reversal of the growth-restriction when co-incubated with mTOR compounds, whilst it was found that these compounds showed no effects under basal culture conditions. Transcriptional changes linked to endochondral growth were assessed and downregulation of Col2 and Acan was observed in hydrogel-treated metatarsi at day 7 . Furthermore, cell cycle analyses confirmed the presence of chondrocytes exhibiting S-G2/M arrest. These data indicate that quasi-static load provokes chondrocyte cell cycle arrest, which is partly overcome by mTOR, with a less marked interaction for NF-kB regulators.

Keywords: endochondral ossification; mTOR; NF-kB; quasi-static; loading; hydrogel

\section{Introduction}

Endochondral growth, which occurs in all skeletal limb elements, involves early mesenchymal cell condensation, as well as sequential proliferation, differentiation into cartilage-forming chondrocytes with linked extracellular matrix (ECM) production, and later, hypertrophy. In this sequence, the cartilage ECM is ultimately calcified and invaded by blood vessels and is thus primed for subsequent ossification. In addition, these endochondral processes are critical at the expanding epiphyses, where long bone lengthening continues until maturity, and are also recapitulated in pathology during bone fracture healing and osteoarthritis. Despite these vital roles, the mechanical factors controlling endochondral growth are incompletely defined, and the signalling pathways via which the emergent mechanics exert local control are only partly resolved.

Endochondral growth chondrocytes which express SRY-box transcription factor 9 (SOX9), bone morphogenic proteins (BMPs) and fibroblast growth factor (FGF) [1-3] are organised with respect to their proximity to the ossifying regions. Resting chondrocytes are more distant, constituting a reservoir of skeletal stem cells expressed under parathyroid 
hormone-related protein (PTHrP) [4]. These undergo sequential proliferation, differentiation, and hypertrophy, with those adjacent to the resting zone dividing intensively, rearranging into columns under PTHrP control, which delays further differentiation. They then enter a post-mitotic phase, synthesising large amounts of aggrecan (ACAN) and collagen-II (COL-II) and expressing Indian hedgehog (IHH) that, in turn, promotes resting zone PTHrP. Chondrocytes near ossifying zones become hypertrophic, at which point they express collagen-X (COL-X), IHH, runt-related transcription factor 2 (RUNX2), alkaline phosphatase (ALPL), matrix metallopeptidase 13 (MMP13) and vascular endothelial growth factor (VEGF) [4-8].

Specific connections between endochondral growth and local mechanical stimuli are emerging. Mechanical stimuli have, for example, been shown to regulate cartilage growth [9-11], and animal models in which movement is restricted show impaired growth [12-16]. Despite these connections, the candidate regulators through which mechanical factors interact to control endochondral growth are ill-defined. Cultured mouse embryo metatarsi are an alternative ex vivo model that avoids systemic effects and the need to contend with the placenta/embryo barrier assay $[17,18]$. Using this embryo metatarsal model, it has been shown that known in vivo skeletal growth promoters, namely growth hormone (GH) and insulin-like growth factor 1 (IGF-I), increase longitudinal expansion [19]. In contrast, this model has disclosed that a PI3K/MEK-ERK pathway inhibitor co-treatment (LY294002/PD98059) severely restricts growth [20], demonstrating that the model is both amenable to exogenous pharmacological intervention and that its use may allow interactions between mechanical stimuli and specific pathways that can be selectively examined.

Inflammation-related pathways can be stimulated by mechanical cues, such as nuclear factor kappa-light-chain-enhancer of activated B cells (NF-kB), a transcription factor which is ubiquitously expressed and central to such responses. NF-kB signalling is connected to Akt, which can serve to activate the mTOR (mTORC1) pathway; this has been shown to contribute to endochondral growth [21-24].

Transcriptional profiling reveals downregulation of mTOR components upon acquisition of mechanical sensitivity of endochondral growth in embryo limbs [25]. These data imply that mTOR activity in individual endochondral growth zones matches the extent to which expansion is controlled mechanically, rather than solely by intrinsic cues. Studies indicating that genetic selection for intrinsically high proliferation and growth rates occurs at the expense of mechanosensitivity [26] support this view. Potential mTOR regulation of cell cycle kinetics via mechanical cues has not hitherto been examined.

It has also been shown that mechanical control of endochondral growth can, however, be regulated by mTOR, which is necessary for the mechanical regulation of embryonic cartilage function [27-30]. NF-kB has also been reported to control normal endochondral growth in limb elements through chondrocyte proliferation and differentiation [31,32]. Here, we explore whether ex vivo imposition of quasi-static load discloses interactions between mechanical stimuli and nutrient-sensing mTOR and / or pro-inflammatory NF-kB pathway signalling in the control of endochondral growth. We examine if mTOR/NF-kB modulators modify endochondral growth and establish a novel hydrogel-based system for the quasi-static loading of metatarsals where mechanical-mTOR/ NF-kB pathway interactions are explored. Assessment of transcriptional markers of endochondral growth and cell cycle kinetics define novel resident chondrocyte behaviours regulated by quasistatic mechanical load and selective pathway interactions.

\section{Results}

2.1. Mouse Metatarsal Growth Is Relatively Insensitive to mTOR and NF-kB Pathway Regulators

Previous studies have used E15 stage mouse metatarsals to examine skeletal dynamics $[17,33-36]$. To establish if metatarsals from a later stage can simplify isolation yet preserve ex vivo growth behaviours, metatarsi from stage E17 embryos were cultured and found to show significant $\sim 40 \%$ length increases (over 14 days), equating to $\sim 3 \%$ /day $(\sim 45 \mu \mathrm{m} /$ day; $\sim 1500 \mu \mathrm{m}$ at the outset). Variation in growth kinetics was seen but a rela- 
tively small overall deviation (6\% coefficient) was evident in individual metatarsi after 14 days. Sensitivity to exogenous factors in E17 metatarsi was confirmed by significant growth inhibition in response to combined LY294002/PD98059 treatment (Figure 1a). Further validation by comparison to post-natal (P0, P5 and P10) in vivo growth showed that metatarsi grew less ex vivo but nonetheless significantly increased their total, mineralization and cartilage zone lengths (Figure 1b); they showed >two-fold increased total lengthening from $\mathrm{P} 0-\mathrm{P} 10$ - which was negligible at early stages (P0-P5), but also showed $>3$-fold mineralisation zone expansion from P5-P10 and, contrastingly, cartilage zone lengthening at only P0-P5 (Figure $1 \mathrm{~b})$. Cartilage zone expansion was the main contributor $(\sim 50 \%$ in vivo) during the 14 days in culture.

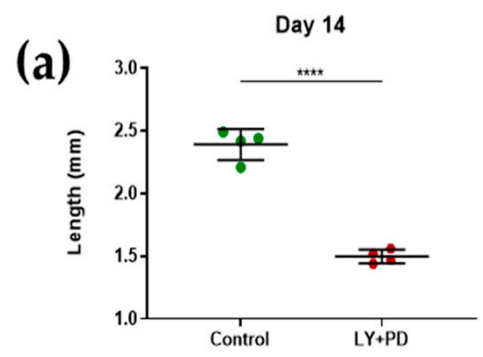

(b)

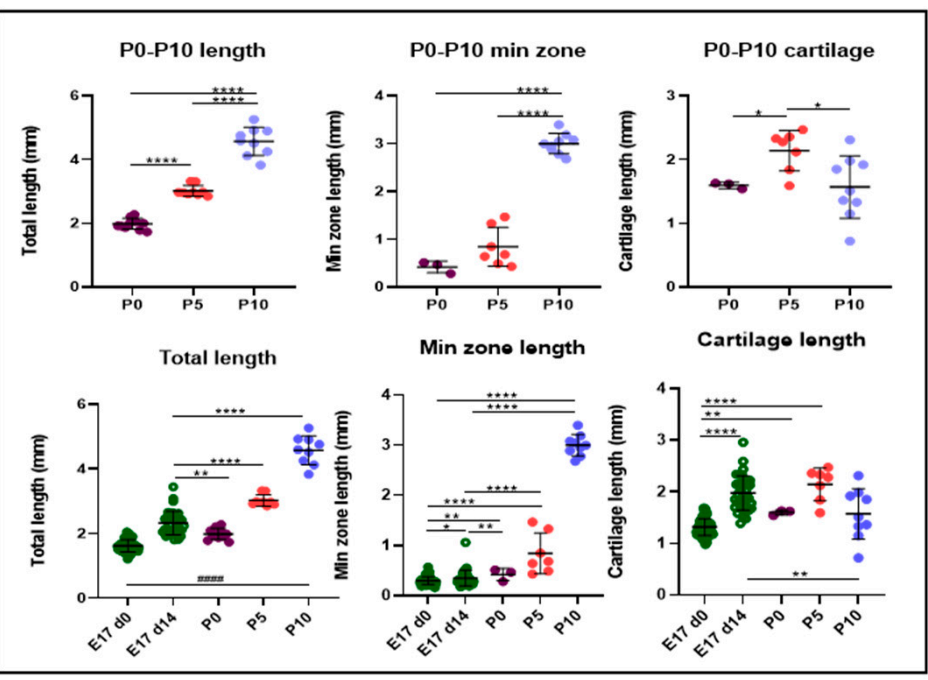

(c)

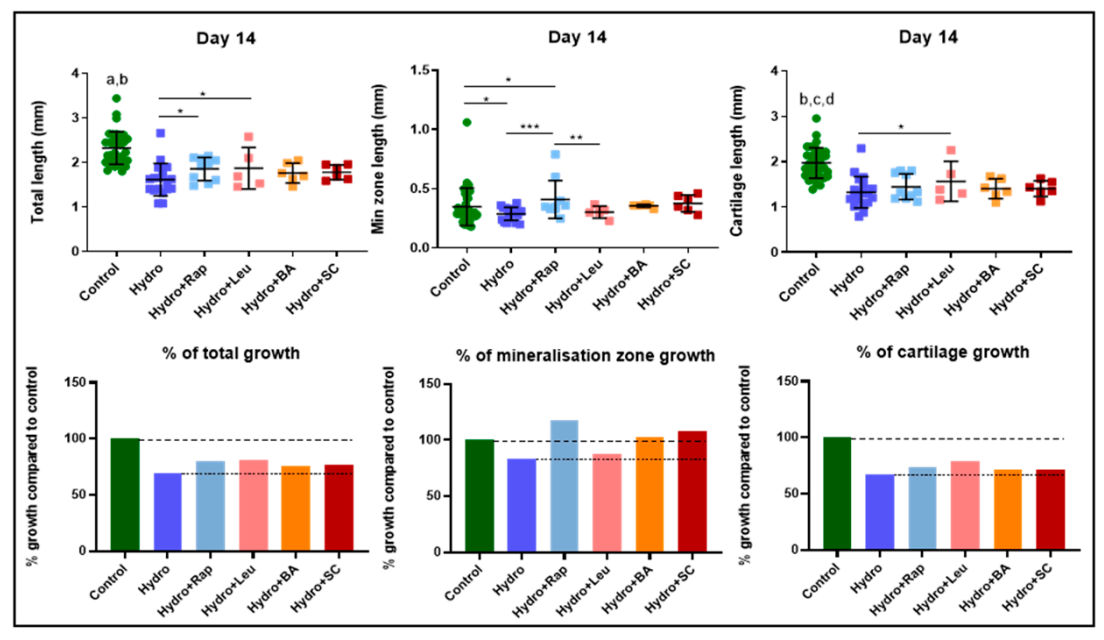

Figure 1. Cont. 

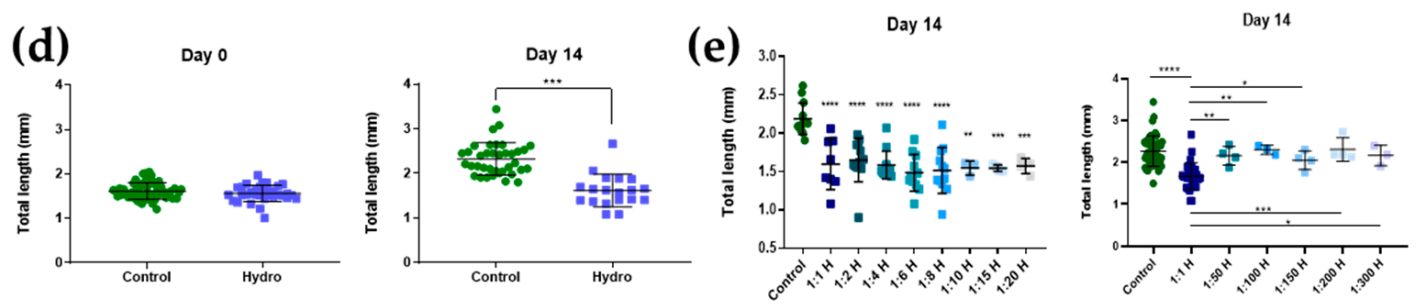

Figure 1. Effects of mTOR/NF-kB compounds and hydrogel on the growth of E17 metatarsi. (a)—differences in total length between control and growth inhibitors LY294002/PD98059. (b)—changes in total, mineralised zone, and cartilage zone lengths in mouse metatarsi at different embryonic and post-natal stages in vivo and comparison with changes during ex vivo maintenance culture. (c) - mTOR modulators, rapamycin, and leucine both somewhat overcome the hydrogel-mediated arrest in longitudinal growth. (d) - quasi-static loading almost completely arrests metatarsal longitudinal growth at days 7 and 14. (e)-hydrogel quasi-static loading shows dose-dependent restriction of longitudinal growth that rapidly switches above dilutions greater than 1:20. Data are presented in intervals that represent the mean and SD. Results were analysed with a linear mixed effect model and ANOVA test according to normality test distribution. Hydro/H-hydrogel; Raprapamycin; Leu-leucine; BA—betulinic acid; SC—SC-514. ${ }^{* * *} p<0.0001,{ }^{* *} p<0.001,{ }^{* *} p<0.01,{ }^{*} p<0.05$, a-control vs. all conditions except hydrogel + leucine $p<0.001$, b-control vs. hydrogel + leucine $p<0.05$, c —control vs. hydrogel and hydrogel + rapamycin $p<0.0001, \mathrm{~d}$-control vs. hydrogel $+\mathrm{BA}$ and hydrogel $+\mathrm{SC} p<0.001$.

Intra-assay screening was used to first identify the concentrations of mTOR/NF-kB regulators that may modify longitudinal murine metatarsal expansion (Table 1); total metatarsal length at day 14 of culture was measured and linear mixed effect statistical analysis was applied. Cumulative data ( $n=8$ experiments) were pooled and the impact of mTOR and NF-kB regulators on total, mineralised and cartilaginous metatarsal zone lengths analysed to reveal that leucine, rapamycin, betulinic acid and SC-514 exhibited no change (vs. controls) in total or cartilage zone length (Figure 1c). Intriguingly, a small yet significant increase in mineralisation zone length in metatarsi treated with the NF-kB inhibitor SC-514 was observed (Figure 1c). These data were strengthened by significant increases in total, mineralised and cartilage zone lengths between days 0-14.

Table 1. Selected modulators of NF-kB and mTOR pathways.

\begin{tabular}{ccc}
\hline Compounds & Function & Concentration \\
\hline Betulinic acid & NF-kB activator & $2.5 \mu \mathrm{M}$ \\
SC-514 & NF-kB inhibitor & $20 \mu \mathrm{M}$ \\
Leucine & mTOR activator & $10 \mathrm{mM}$ \\
Rapamycin & mTOR inhibitor & $100 \mathrm{nM}$ \\
Vitrogel 3D & Quasi-static loading & $1: 1$ dilution \\
\hline
\end{tabular}

\subsection{Interaction between Quasi-Static Loading and mTOR Modulates Endochondral Growth}

Initial long-term growth monitoring identified VitroGel3D ${ }^{\mathrm{TM}}$ as a suitable hydrogel through which quasi-static load could be delivered. This was apparent in the resistance placed upon the longitudinal metatarsal expansion that would otherwise have occurred under ex vivo conditions. This hydrogel was the most practical way of testing mechanics in these embryonic tissues. Metatarsi maintained in a 1:1 hydrogel solution showed an almost total arrest of longitudinal expansion during the 14 days (control $2.32 \pm 0.36$ and hydrogel $1.62 \pm 0.37$, mean $\pm S D$; Figure $1 \mathrm{~d}$ ). Based on this restriction upon expansion, and assuming linear growth, these hydrogel conditions represent the imposition of quasi-static compressive strains of $\sim 30.4 \%$ over 14 days, which equates to strain rates of $\sim 2 \%$ /day or $\sim 900 \mu \varepsilon / \mathrm{hz}$. To interrogate the effects of hydrogel concentration, metatarsi were maintained in varying dilutions (1:1-1:300). This resulted in a full growth arrest in dilutions up to 1:20, with a sharp decline in growth arrest at the 1:50 dilution, wherein metatarsi gained lengths similarly to controls; hereafter, data from the 1:1 dilution are reported, unless otherwise stated (Figure 1e). 
To test if the quasi-static load interacts with mTOR and NF-kB pathways to regulate endochondral growth, the influence of leucine, rapamycin, betulinic and SC-514 was reexplored in the presence of hydrogel-mediated growth restraint. This revealed significant interactions with mTOR, as addition of rapamycin not only produced greater rates of total length-wise growth but also greater lengthening of the mineralisation zone than in hydrogel alone (Figure 1c). Similar data were intriguingly observed when metatarsi were supplemented with leucine, which caused significantly greater total lengthening (than hydrogel alone), but unlike rapamycin, instead generated significant increases in cartilage zone length only (Figure 1c). Changes in total, mineralisation and cartilage lengths were consistently higher in metatarsi cultured in a combination of either leucine or rapamycin and hydrogel (vs. hydrogel alone; Figure 1c). In contrast, the NF-kB modulators SC-514 and betulinic acid did not modify any parameter in the presence of hydrogel-induced quasi-static restraint. These data indicate significant mTOR pathway interactions with quasi-static load in the control of EO.

Arrests in metatarsal growth by hydrogel may involve changes in cell proliferation, viability, or survival. To explore this further, PCNA labelling and whole-mount 3D confocal microscopy was performed to pinpoint chondrocytes in the S-phase [37]. This (PCNA, red; nuclear DAPI, blue; co-labelling white) showed little if any reduction in PCNA labelling in hydrogel-treated samples (vs. control; Figure 2a). Quantification of total volume $\left(\mu \mathrm{m}^{3}\right)$ and mean fluorescence intensity showed that the mean PCNA and DAPI labelling intensity was greater in hydrogel-treated metatarsi, indicating a greater density or closer packing of S-phase chondrocytes under quasi-static load conditions (Figure 2a). Assays employed to determine resident chondrocyte viability demonstrated that chondrocytes in control and hydrogel-treated metatarsi were labelled predominantly 'live', with little, if any, 'dead' cell labelling (Figure 2b). Assessment of FITC/Texas Red cell labelling intensity $\left(\mathrm{RFU} / \mu \mathrm{m}^{2}\right)$ showed that metatarsi in hydrogel (14 days) did not exhibit changes in viability nor greater levels of cell death than controls (Figure $2 b$ ). These data suggest that hydrogel-related growth arrest does not involve changes in resident cell proliferation, viability, or survival.

\subsection{Transcriptional Analyses Support the Interplay between Quasi-Static Mechanical Load and mTOR Pathway Signalling in the Control of Endochondral Growth}

We also assessed mRNA expression levels linked to endochondral growth by multiplex qRT-PCR in metatarsi cultured in hydrogel, with genes arbitrarily organised based on their relatedness to the matrix content (Col2, Acan, Col10, Alpl, Mmp13, Tbsp4) or their established regulatory roles (Pthrp, Sox9, Ihh, Runx2, Vegf, Akt and Il6). Principal component analysis demonstrated the presence of three major clusters, comprising: (i) Acan, Alpl, Col10 and Mmp13; (ii) Runx2, Col2, Sox9 and Akt; and (iii) Ihh and Pthrp, respectively, with three outliers (Vegf, Il6, Tbsp4; Figure 3a). Col2 and Acan alone were found to confer 72\% of total variance, and exploration of the scale and direction of the interactions using a correlation matrix reinforces the three major clusters. Col2 and Acan showed significant decreases in hydrogel at day 7 (Figure 3b). Mmp13 levels were significantly lower in hydrogel + rapamycin treatment than hydrogel-treated metatarsi at day 7 , and yet were raised in hydrogel + leucine compared to hydrogel alone at day 14 (Figure 3c). Il6 levels were significantly lower in hydrogel + leucine than in hydrogel alone (Figure 3d), which aligns with the raised IL-6 protein levels measured in media conditioned by metatarsi in hydrogel (vs. levels with mTOR modulators added; Figure 3d). These data suggest that quasi-static load reveals the mechanical interplay between mTOR pathway signalling components in the regulation of endochondral metatarsal growth. 


\subsection{Quasi-Static Loading Induces Chondrocyte S to G2/M Cell Cycle Arrest}

Changes in cell cycle kinetics were examined at 5, 7 and 14 days under control and hydrogel conditions using propidium iodide labelling/flow cytometry. Gating was used to define four putative chondrocyte populations: pre-hypertrophic (P2); proliferative (P3), hypertrophic (P4) and all these populations combined (designated P1). Analysis of P1 showed (Figure 4a) that the percentage of cells in G0/G1 was higher at day 5 and steadily declined at day 7 and 14 in both controls and hydrogel (Table 2); this shift indicates a progression to a raised proportion of cells in G2/M. The percentage of total cells (P1) in S phase was also consistently greater in hydrogel, indicating a prolongation of the $S$ phase. P2 displayed no cells in G0/G1, and a vast proportion in the G2/M phase; the percentage of cells in each of these phases was similar in controls and hydrogel, with fewer cells in the $S$ phase with prolonged culture-particularly between days 5 and 7 (Table 2).

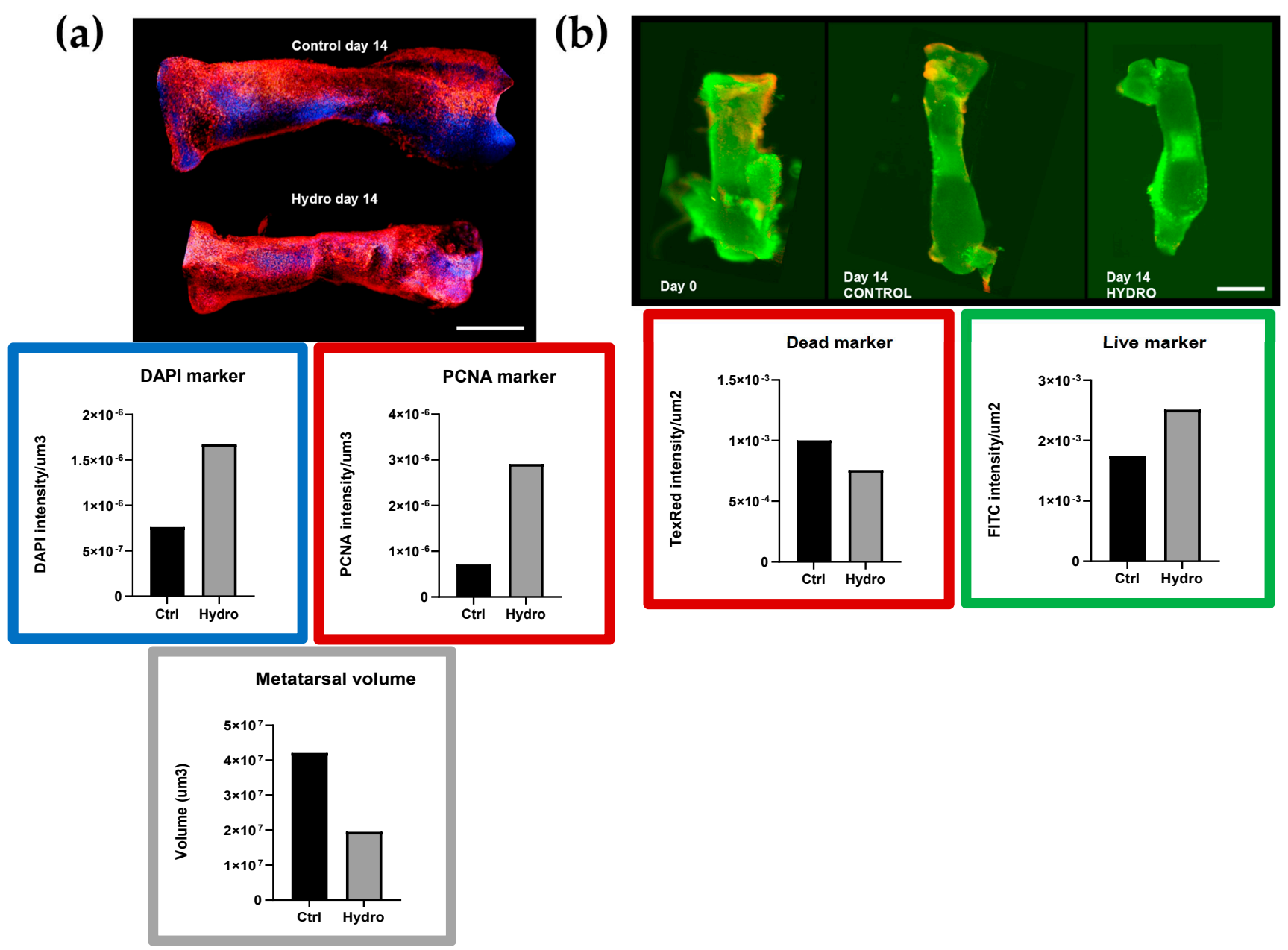

Figure 2. Metatarsi stained for PCNA and Live/Dead cell labelling. (a)—cultured metatarsi in hydrogel show high levels of PCNA staining at day 14. PCNA 3D confocal whole-mount imaging of metatarsi for proliferation assays, showing DAPI (blue box) and PCNA (red box) mean channel intensity per $\mu \mathrm{m}^{3}$ of volume. Hydrogel displays higher mean values than the control for both. (b) - metatarsi cultured in hydrogel label positively for viable cells at day 14. 2D fluorescence imaging of metatarsi for live/dead assay (viability). Differences in cell death between control and hydrogel using mean intensity of Texas Red channel per $\mu \mathrm{m}^{2}$ of area (red box) and live cells using mean intensity of FITC channel per $\mu \mathrm{m}^{2}$ of area (green box). Hydrogel displays less cell death and brighter live staining than controls. These data are a representation of observations made using 3D live/dead exclusion assay in $>1$ tarsals. For quantification, 1 sample per condition was analysed. Ctrl—control; Hydro—VitroGel3D hydrogel; Scale bar $=5 \mathrm{~mm}$. 

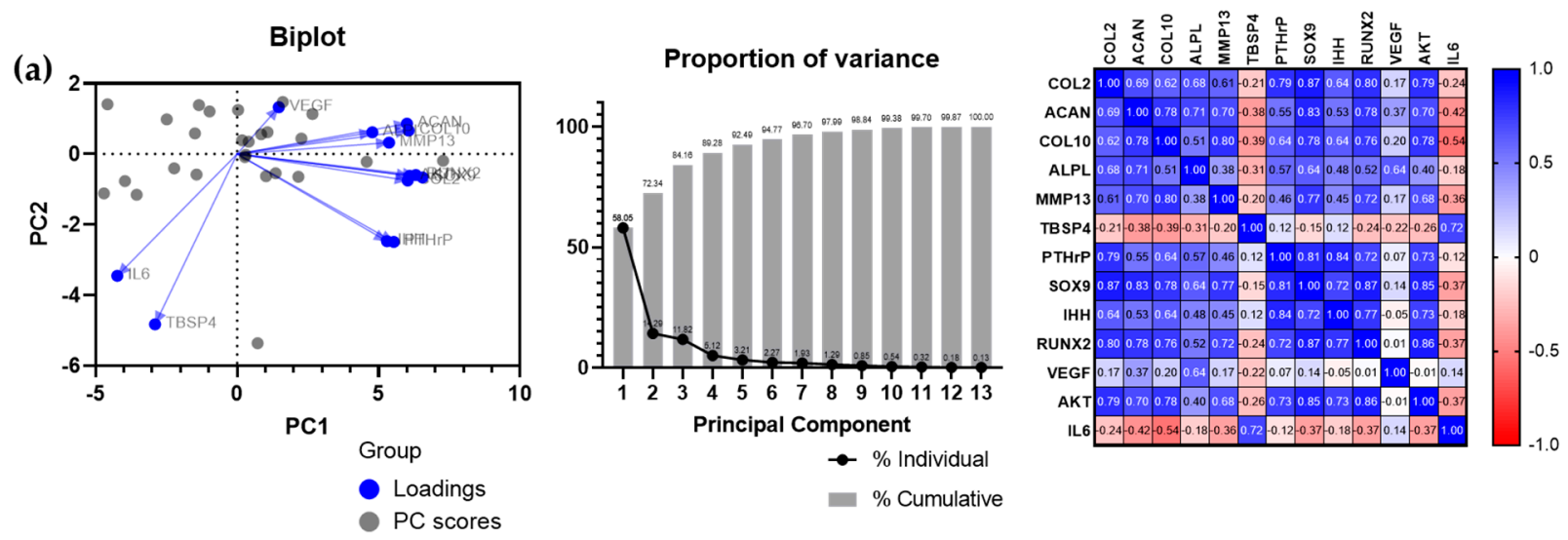

(b)

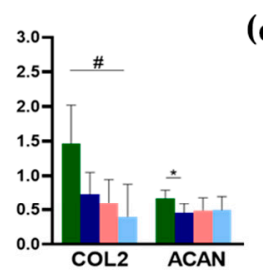

(d)

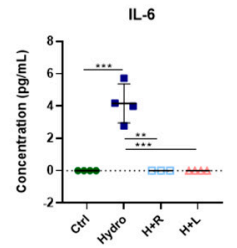

(c)
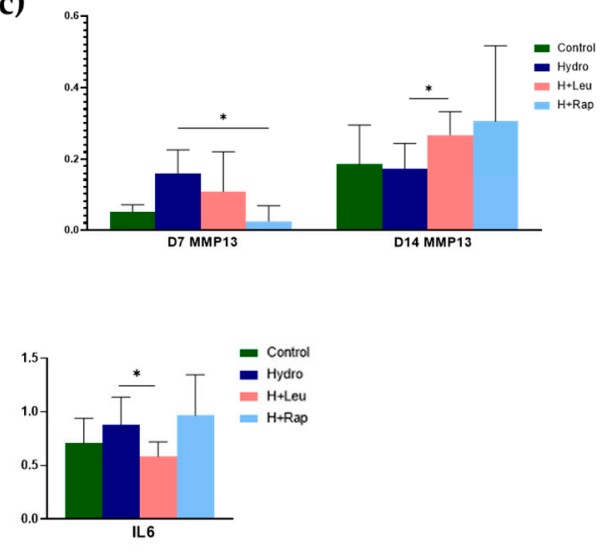

Figure 3. mRNA expression shows that hydrogel quasi-static loading interacts with the mTOR pathway. (a) - characterisation of multiplex RT-PCR results using principal component analysis, which shows that variance in dataset can be explained mostly by changes in Col2 and Acan mRNA levels. Biplot showing principal component (PC) 1 and 2, Col2 and Acan, respectively, along with their PC scores; this shows that most genes in the EO multiplex behave similarly, except for Vegf, Il6 and Tbsp4. PCs 1 and 2 (Col2 and Acan) together account for $72 \%$ of variance in the dataset, which increases to $84 \%$ with the addition of PC3 (Col10). Heatmap shows the 13 analysed genes with PC scores and how they correlate. (b)—day 7 Col2 and Acan mRNA levels are downregulated in the hydrogel condition. (c)—Mmp13 mRNA levels at days 7 and 14 show modulation by either leucine (day 7) or rapamycin (day 14). (d)-IL-6 protein levels determined by ELISA in culture supernatants (left). Marked increases in IL-6 levels were seen in media conditioned by metatarsals in hydrogel. Il6 mRNA levels were downregulated by leucine when added to hydrogel (right). For mRNA, $n=2-6$ samples per condition. Data are presented as mean and SD. Results were analysed with ANOVA and t-tests according to normality test distribution. IL-6 ELISA was analysed using Grubbs method of outlier calculation on GraphPad Prism. ${ }^{* * *} p<0.001$, ${ }^{* *} p<0.01,{ }^{*} p<0.05, \# p<0.05$ between control and all conditions. Ctrl-control; Hydro-hydrogel; Rap-rapamycin; Leu-leucine; $\mathrm{H}+\mathrm{R}$-hydrogel + rapamycin; $\mathrm{H}+\mathrm{L}$-hydrogel + leucine. 
(a)
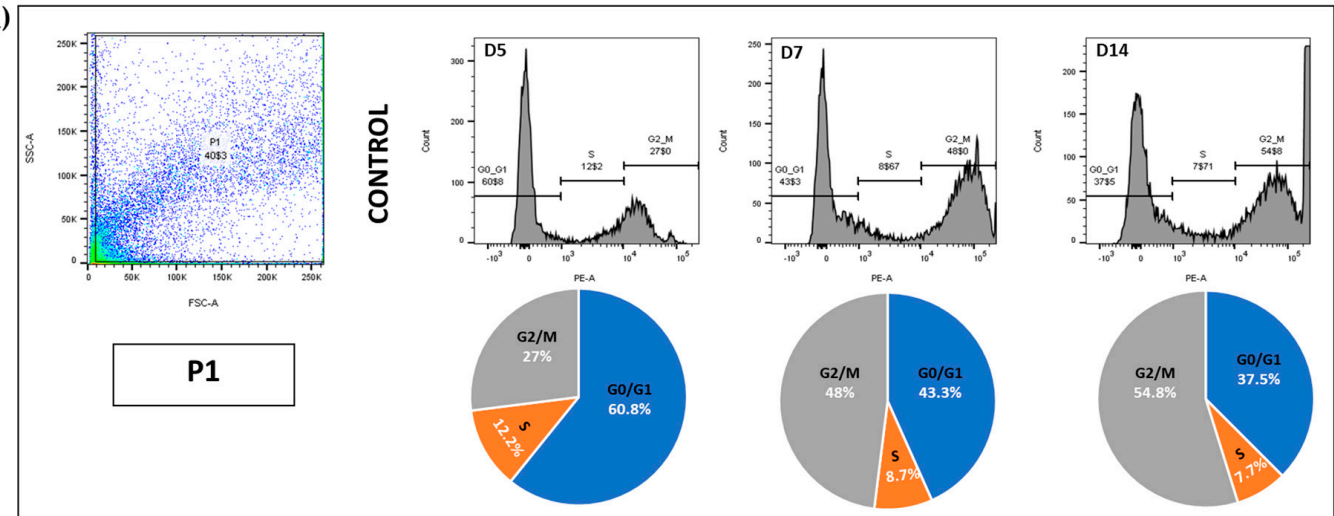

P1
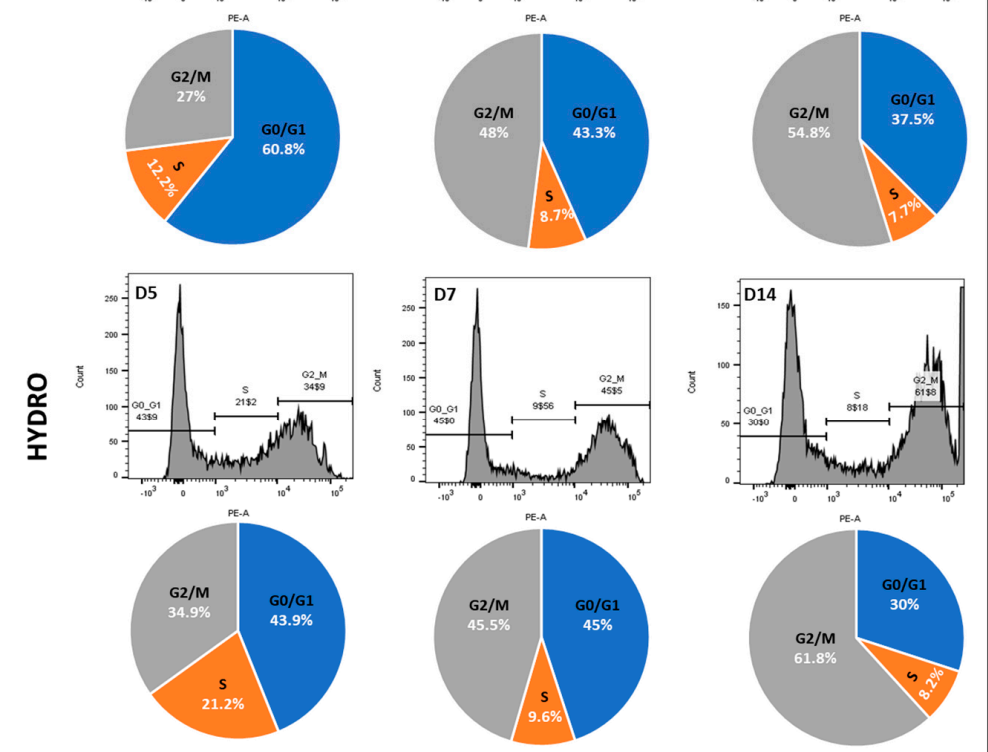

(b)

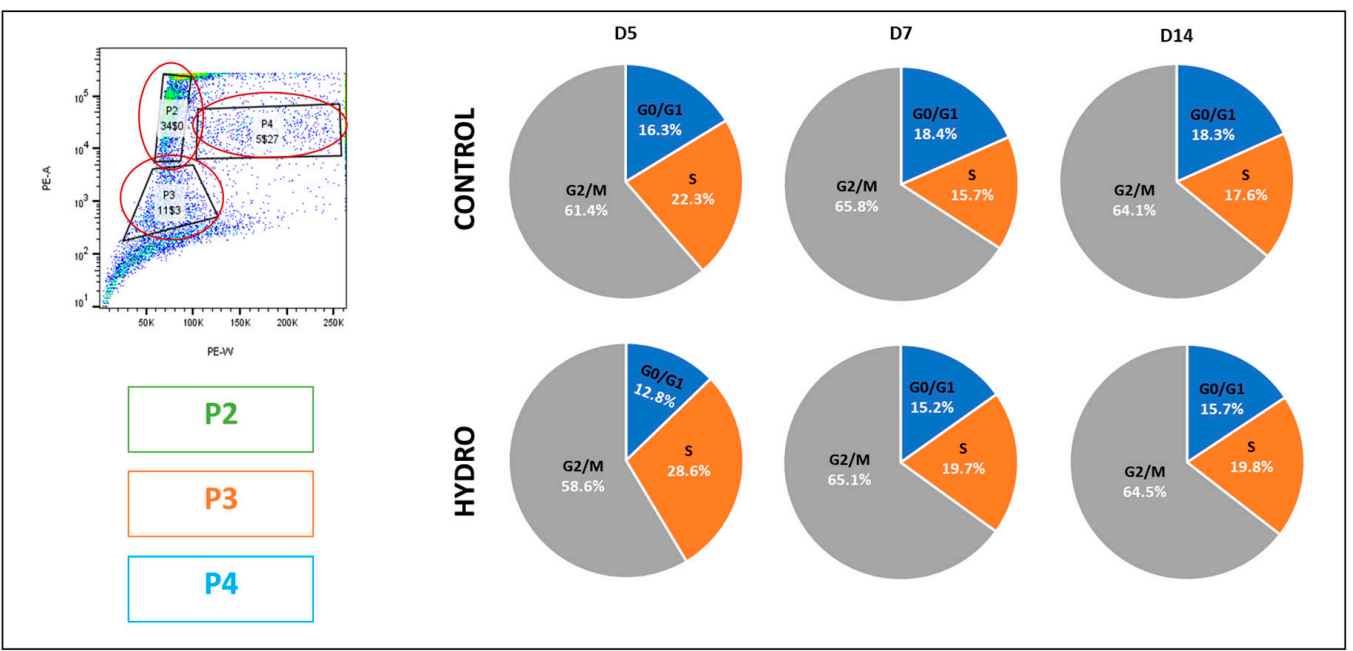

Figure 4. Representations of PI-labelled P1 and P2-P4 populations as scatter plots and d5, d7 and d14 as histograms. (a) - representation of the PI-labelled P1 population as a scatter plot and d5, d7 and d14 as histograms. Pie charts represent the proportion of the total number of cells in each cell cycle phase (G0/G1, S and G2/M) in cell populations isolated from metatarsals maintained for 5 (left), 7 (middle) and 14 (right) days in the absence (control) and presence (hydro) of hydrogel quasi-static loading conditions. (b) -representation of the PI-labelled P2-P4 populations pooled together as a scatter plot and d5, d7 and d14 pie charts. Pie charts represent the proportion of the total number of cells in each cell cycle phase (G0/G1, S and G2/M) in cell populations isolated from metatarsals maintained for 5 (left), 7 (middle) and 14 (right) days in the absence (control) and presence (hydro) of hydrogel quasi-static loading conditions. Data were analysed using BD FACSDIVA and FlowJo. Ctrl—control; Hydro-hydrogel; d5—day 5; d7—day 7; d14-day 14; SSC-A—side scatter area; FSC-A—forward scatter area; PE-A—phycoerythrin fluorescent dye area; PE-W—phycoerythrin fluorescent dye width. 
Table 2. Summary of the cell cycle analysis of control and hydrogel conditions at days 5, 7 and 14. Hydro-hydrogel; $\mathrm{P}$-population.

\begin{tabular}{|c|c|c|c|c|}
\hline \multirow[b]{2}{*}{ Day/Cycle Phase } & \multicolumn{4}{|c|}{ Control vs. Hydro (\%) } \\
\hline & $\begin{array}{c}\text { P1 } \\
\text { (All Cells) }\end{array}$ & $\begin{array}{c}\text { P2 } \\
\text { (Pre-Hypertrophic) }\end{array}$ & $\begin{array}{c}\text { P3 } \\
\text { (Proliferative) }\end{array}$ & $\begin{array}{c}\text { P4 } \\
\text { (Hypertrophic) }\end{array}$ \\
\hline Day 5/G0 and G1 & 60.8 vs. 43.9 & 0 & 48.9 vs. 38.3 & 0 \\
\hline $5 / \mathrm{S}$ & 12.2 vs. 21.2 & 15.8 vs. 14.6 & 51.1 vs. 61.7 & 0 vs. 9.5 \\
\hline 5/G2 and $\mathrm{M}$ & 27 vs. 34.9 & 84.2 vs. 85.4 & 0 & 100 vs. 90.5 \\
\hline Day 7/G0 and G1 & 43.3 vs. 45 & 0 & 55.3 vs. 45.7 & 0 \\
\hline $5 / \mathrm{S}$ & 8.7 vs. 9.6 & 2.5 vs. 4.7 & 44.7 vs. 54.3 & 0 \\
\hline 5/G2 and $\mathrm{M}$ & 48 vs. 45.5 & 97.5 vs. 95.3 & 0 & 100 \\
\hline Day 14/G0 and G1 & 37.5 vs. 30 & 0 & 54.9 vs. 47.1 & 0 \\
\hline $5 / \mathrm{S}$ & 7.7 vs. 8.2 & 2.3 vs. 2.9 & 45.1 vs. 52.9 & 5.5 vs. 3.6 \\
\hline 5/G2 and $M$ & 54.8 vs. 61.8 & 97.7 vs. 97.1 & 0 & 94.5 vs. 96.4 \\
\hline
\end{tabular}

In contrast, P3 contained no cells in the G2/M phase, and consistently more in the S phase in metatarsals maintained in hydrogel (vs. control) at all time-points (Table 2). P4 comprised an almost exclusive subdivision to G2/M and few S phase cells, and no G0/G1 phase was identified. Again, the most marked hydrogel-induced shift was observed on day 5, when marked increases in S phase cells were evident (Table 2). Pooling of P2-P4, as expected, agreed closely with data from P1 (Figure 4b). These data show that the hydrogel induced an expansion of cells in the $S$ phase, most markedly on day 5 , which was most pronounced in the smallest chondrocytes, in which these increases seem to be at the expense of time spent in G0/G1.

\section{Discussion}

Our findings show: (i) that E17 metatarsi preserved a scope for ex vivo growth equivalent to $50 \%$ of the in vivo rate and showed sensitivity to known endochondral growth inhibitors (LY294002/PD98059); (ii) that neither mTOR nor NF-kB regulators affected growth under basal conditions; (iii) that quasi-static load via hydrogel exerted growth arrest, which was reversed by mTOR but not by NF-kB modulators; and, finally, (iv) that hydrogel-related growth restraint was linked to an S-G2/M cell cycle arrest, itself linked to ECM (Col2, Acan, Col10) transcriptional changes-with those linked to hypertrophy (Col10, Mmp13) also exhibiting a corresponding reversal by mTOR modulators. We conclude that an applied mechanical cue discloses interactions with the nutrient-sensing mTOR pathway to control endochondral growth by regulating cell cycle progression and hypertrophy of resident chondrocytes.

Our knowledge of the mechanical regulation of endochondral growth remains somewhat sparse and is abridged by the Heuter-Volkmann law: static compression slows, and static tensional forces accelerate longitudinal growth. Studies using load protocols in rat vertebrae and ulnas and porcine mesenchymal stem cells have recently reinforced this view by showing that cyclic tensile strain promotes EO [10], and that both axial loading [38] and static and dynamic compression, likewise, suppress longitudinal growth [39]. The quasistatic loading system we have used regulates endochondral expansion ex vivo in a tuneable system for controlled growth regulation. This gives new awareness of and allows questions concerning the interactions between pharmacological interventions and mechanical cues to be tested readily ex vivo. This has allowed us to disclose a novel interaction between the nutrient-sensing mTOR pathway and mechanics in the regulation of endochondral growth. Our findings additionally indicate that such an interaction is less extensive via the pro-inflammatory NF-kB signalling pathway and provides insights into the mechanisms by which this mechanical crosstalk is achieved in resident cartilage chondrocytes.

Culturing of metatarsi under basal conditions has revealed that activators/inhibitors of mTOR signalling do not to modify any parameters of growth; only SC-514-mediated 
NF-kB modulation resulted in increased mineralisation zone length. Previous studies have shown that SC-514 does not reduce hypertrophy in human osteoarthritic chondrocytes [40], and that the NF-kB signalling pathway can control chondrocyte differentiation [41]. Furthermore, it has been reported that differentiated osteoblasts generate increased trabecular bone mass and higher bone mineral density in circumstances where the IKK gene was likewise inhibited [42]. This has been extended by ex vivo studies in which SC-514 increased mineralisation by attenuating osteoclast function but also by influencing osteoblastogenesis [43]. These data suggest that basal NF-kB activities restrict mineralisation and that their inhibition by SC-514 promotes accelerated levels of mineralisation.

Activators/inhibitors of mTOR signalling did not modify growth under basal conditions. Rapamycin is the best studied of the mTOR inhibitors and leucine is a wellestablished, natural mTORC1 mTOR complex activator. The lack of any significant effects of rapamycin on longitudinal growth ex vivo may also have been due to the concentration used. Rapamycin differentially targets mTORC1 and mTORC2 in a concentrationdependent manner. Thus, $100 \mathrm{nM}$ rapamycin may be low enough to have not inhibited either mTORC1/2, and this is known to allow for compensatory mTOR pathway activation. It has been found that leucine targets mTORC1 to activate cell synthesis and proliferation to accelerate muscle growth $[44,45]$. There are no studies reporting the effects of leucine on embryonic endochondral growth. It is possible that leucine does not promote growth in metatarsals due to constitutive mTOR activation under ex vivo conditions, where nutrient availability in the media is not limiting. In contrast to mTOR, NF-kB is an inflammatory pathway regulated by exogenous betulinic acid, which has reported inhibitory or stimulatory activity that depends on cell type and concentration [46-48]. Despite this, no effects on endochondral growth were seen with addition of betulinic acid to metatarsal cultures. Other studies using bone cells in vitro have found that $10-15 \mu \mathrm{M}$ and $10 \mathrm{mM}$ betulinic acid induce bone formation by enhancing BMP2 [49], and inhibit osteoclastogenesis via RANKL [50], respectively. Herein, betulinic acid was used at $2.5 \mu \mathrm{M}$, which might be too low to exert any effects on endochondral growth in the context of an ex vivo organ culture system, which likely shows different requirements to cultured cells in vitro.

Our data reveal a very dramatic mechanically-engendered inhibition of longitudinal growth in hydrogel, suggesting that prolonged static compressive loads may evoke an irreversible blockade of EO. Studies in chick embryos have shown that the effects of 'rigid' paralysis at early embryo stages, which would likewise engender quasi-static load, could be partially overcome in the spine, but not in developing joints, by restoring movement [16]. This suggests that the dynamic loads associated with movement may reverse some of the effects of quasi-static loading. The effect of quasi-static load imposed by hydrogel may also be reversed if appropriate dynamic stimuli were restored to cultured metatarsi, and perhaps the differences in longitudinal expansion observed may be attributable to the lack of dynamic loading when the metatarsals are maintained in isolation.

Dilution of hydrogel showed a potential for concentration-dependent growth inhibition. Recent studies have shown the importance of hydrogel stiffness in chondrogenic differentiation and growth, highlighting that the composition and loading regimes are crucial [51,52]. It has been shown that lower stiffnesses, along with higher mesh sizes, allow for larger molecules to diffuse and glucose and oxygen rates to be maintained $[53,54]$. The fact that 1:20 vs. 1:1 dilution exert similar restraints on longitudinal expansion suggests that this rescue is more likely due to mechanical interactions with the mTOR and NF-kB pathways than to diffusion. The results obtained for the 1:20 hydrogel dilution clearly indicate that the hydrogel density is an important factor and that the 'tunability' of the quasi-static loading system is a vital asset. Neither betulinic acid nor SC-514 exerted any modification of growth at the 1:1 hydrogel dilution. Dynamic load stimuli are known to activate or suppress NF-kB signalling in chondrocytes in vitro depending on their magnitude [55]. The quasi-static loading for 14 days used here may thus represent a relatively mild loading regime with regard to activation of NF-kB. Although betulinic acid and SC-514 had no effect, mTOR regulators, leucine and rapamycin did; partial reversal of the hydrogel-related 
growth restraint by these pharmacological mTOR pathway modulators suggests that there is a requirement that the system is perturbed-here, slowed by hydrogel—in order that mTOR's role in maintaining the status quo can be made apparent.

This was also true in the quantification of early and late transcriptional EO-marker mRNA levels. The differences in mRNA levels in metatarsals maintained in hydrogel (vs. control) were more evident at day 7, targeting resting chondrocytes (Col2 and Acan). In all cases, except for $M m p 13$, a downregulation of mRNA levels was seen in hydrogel-treated metatarsi on day 7 and no differences were seen at day 14. Furthermore, addition of leucine at day 14 promoted upregulation of Col10 and downregulation of $I l 6$ mRNA levels. Together, these results suggest three key changes in mRNA levels: Col2, Acan and Col10, with all three suppressed by hydrogel and exhibiting scope for reversal back to control levels of expression upon mTOR modulator intervention.

The upregulation of the NF-kB marker IL-6 in culture supernatants in the presence of hydrogel may be interpreted as evidence for a stress-induced response due to quasi-static load. This would likely be via chronic NF-kB pathway activation. Intriguingly, these hydrogel-induced levels of IL-6 release were blocked by the addition of either leucine or rapamycin, which strongly supports the view that crosstalk between mTOR/NF-kB exists in the metatarsal only under quasi-static load conditions.

This raises questions about the mechanisms that conserve the long-term viability of resident chondrocytes when growth is significantly limited. Analysis of cell cycle kinetics under quasi-static load conditions exposed an $\mathrm{S}$ to G2/M phase arrest, which was more evident in the P3 (proliferative) cell population. Cells in metatarsals within the hydrogel are subjected to what amounts to a continuous compression, which may be translated into a signal instructing how much expansion cells should undergo. To promote longitudinal growth, chondrocytes must proliferate and the data from our cell cycle analyses indicate that this proliferation was halted at $S$ phase by the stiffness of the hydrogel. It is tempting to speculate that the level of proliferation under these quasi-static load conditions maintains sufficient chondrocyte renewal rates and viability, but that less than this would facilitate a significant increase in length. The cell cycle can also be arrested due to DNA damage. If prolonged quasi-static loading induces DNA damage/stress, then arrest at cell cycle checkpoints will ensure a halt upon division. Several checkpoints are enforced during the cell cycle, and one of them is during $S$ phase: the DNA damage checkpoint. This checkpoint functions to coordinate DNA replication and repair and cell cycle progression [56]. Thus, chondrocytes in these quasi-statically loaded metatarsi appear not to successfully complete this $S$ phase checkpoint, resulting in a delay in chondrocyte proliferation until DNA damage is successfully repaired and conditions to facilitate cell cycle progression are again met. It remains to be seen whether these mechanisms underpin the rescue of growth achieved by mTOR modulators at 1:20 hydrogel dilutions. It is also apparent that the tunability of the system and the apparent reversibility of the effects of hydrogel may be exploited to more fully address these mechanisms.

\section{Materials and Methods}

\subsection{Mice}

All animal procedures were performed in accordance with the Home Office guidelines in the UK, the Animals (Scientific Procedures) Act 1986, under PPLs 70/7859, P253385BB2, and PIL I5FB864C0, and were approved by the Royal Veterinary College's ethics committee. Endochondral ossification was studied in vitro using an established model [17]. This involved maintenance of a colony of C57BL/6J mice in the Biological Services Unit, Royal Veterinary College, housed with regulated humidity and a $12 \mathrm{~h}$ light and dark cycle under an appropriate breeding programme in a conventional facility, and embryos collected using an established protocol from pregnant mice at day E17 [17]. 


\subsection{Mouse Metatarsal Organ Culture Model}

Briefly, pregnant mice were euthanized by cervical dislocation and embryos were harvested immediately and euthanized by decapitation. The embryos were immediately placed in $50 \mathrm{~mL}$ tubes containing sterile PBS (Gibco, Waltham, MA, USA). Once all embryos had been collected, they were transferred to Petri dishes and both hind limbs were separated from the body using scissors. Once hind limbs were collected, they were transferred in sterile PBS to be viewed under a dissection microscope, and with the legs held in place using forceps, the skin was removed from the entire limb and the phalanges removed by pinching and pulling until the metatarsi were exposed using fine forceps (F.S.T. Dumont \#4 and \#5, Heidelberg, Germany). Second, the third and fourth metatarsi (numbers 2-4, middle) were collected, leaving the perichondrium intact but removing any extraneous soft tissues, and transferred into a new Petri dish containing 1X PBS, and the remaining bones of the limb discarded.

After collecting all the metatarsi from all of the pups from each pregnant mouse ( $\sim 7$ pups), each metatarsus was moved using small forceps to an individual well in a 24-well plate containing $\alpha$-MEM culture media with or without supplementation; media was changed every other day and cultures maintained for 14 days in medium containing $0.2 \%$ BSA (Sigma-Aldrich, St. Louis, MO, USA), $5 \mu \mathrm{g} / \mathrm{mL}$ L-ascorbic acid phosphate (Wako, Osaka, Japan), $0.05 \mathrm{mg} / \mathrm{mL}$ gentamicin (Gibco, Waltham, MA, USA) and $1.25 \mu \mathrm{g} / \mathrm{mL}$ amphotericin B (Gibco, Waltham, MA, USA) [17].

\subsection{Pharmacological Manipulation of Murine Metatarsi}

To study the effects of pharmacological manipulation of specific chosen pathways, metatarsals within individual wells were cultured in basal medium supplemented with either: (i) $100 \mathrm{nM}$ rapamycin (MedChem Express, Sollentuna, Sweden), (ii) $2.5 \mu \mathrm{M}$ betulinic acid (Abcam, Cambridge, UK), (iii) $20 \mu \mathrm{M}$ SC-514 (Abcam, Cambridge, UK) or (iv) $10 \mathrm{mM}$ leucine (Sigma-Aldrich, St. Louis, MO, USA) [8], or (v) $10 \mu \mathrm{M}$ LY294002 (LY) and PD98059 (PD; Abcam, Cambridge, UK), after stable ex vivo cultures were established. Medium was replenished every other day. NF-kB is associated with its inhibitor, IkB $\alpha$, when inactive; its activation involves phosphorylation of the IkB kinase (IKK) complex to release NF-kB, leading to nuclear translocation and modified transcription [57]. IKK can be modulated by SC-514, which selectively inhibits NF-kB phosphorylation to block activation; whilst it may be stimulated by betulinic acid, which promotes NF-kB-mediated transcriptional activity [46,58-62]. mTOR, which is comprised of mTORC1 and mTORC2 complexes, coordinates growth and cell division in response to nutritional and growth factor status. mTORC1 contains the regulatory protein Raptor sensitive to rapamycin and is a key growth factor as well as a mediator of insulin. In contrast, mTORC2 contains the rapamycininsensitive protein Rictor, and instead activates NF-kB via Akt. mTORC1 is thus inhibited by rapamycin and is stimulated by exogenous leucine, which acetylates Raptor via acetylcoenzyme A [44]. These pathways are thus subject to exogenous regulation and show scope for extensive crosstalk [63]; NF-kB can function downstream of Akt (inhibiting mTORC1 suppresses NF-kB) but also serve as an upstream regulator of mTOR (IKK activates mTORC1/2; [64].

\subsection{Mechanical Manipulation of Murine Metatarsi}

Additional studies were designed to explore the effects of imposing quasi-static load during growth. This involved the incubation of embryonic mouse metatarsals in both the absence or presence of VitroGel ${ }^{\mathrm{TM}} 3 \mathrm{D}$ (The Well Bioscience Inc, North Brunswick, NJ, USA). At the 14-day endpoint, metatarsi were placed in RNA later ${ }^{\mathrm{TM}}$ solution (Invitrogen, Waltham, MA, USA) for subsequent RNA extraction and analysis.

\subsection{Quantification of Change in Element Length}

Photographs of individual metatarsi were taken using a Leica camera adapter on a Leica MZ apo stereo zoom microscope twice each week, to allow for the measurement of 
the bones' length with ImageJ software on specific days during in vitro culture. All sessions also involved identical image capture of a graduated ruler positioned in the sample plane for calibration. For measurement, each photo was opened and calibrated in ImageJ $1.48 \mathrm{v}$ (National Institute of Health, Bethesda, MD, USA) and a straight line used to measure total metatarsal length from distal to proximal extremities. Measurements were also recorded for the length of the mineralizing zone, and subtraction of this mineralised zone length from the total length provided a measure of the cartilage length to yield measurements of the total, mineralised and cartilage zone lengths.

\subsection{Sample Size and Individual Experiments in Metatarsi Length}

Analysis was performed both within individual experiments and in pooled experiments; full information regarding both the total number of metatarsi and number of experimental replicates is provided within each figure legend. Individual experiments were mostly used to provide either confirmatory data, or pilot data regarding the specific effects of a compound or the exploration of singular timepoints. Pooled data from numerous metatarsi from across several replicate experiments with high sample sizes were used to explore the overall effect; appropriate statistical approaches were employed for each.

\subsection{Live/Dead Assay}

To investigate the viability of the cells in the cultured metatarsi, a Live/Dead assay (Abcam, Cambridge, UK) was carried out following the manufacturer's instructions. Accordingly, metatarsi collected immediately after dissection and the establishment of cultures (day 0) and after 14 days of maintenance under standard culture conditions, were stained with $5 \times$ Live and Dead Cell stain in DMSO in $300 \mu \mathrm{L}$ of $1 \times$ sterile PBS, and incubated for $10 \mathrm{~min}$ at RT. After the incubation, samples were imaged on a Leica DM4000 upright fluorescence microscope (Leica Biosystems, Nussloch, Germany) with a Zeiss mRM camera using Zeiss ZEN 3.1 blue edition software (Carl Zeiss Microscopy GmbH, Munich, Germany) with L5 (green fluorescence) and TX (red fluorescence) channels.

To quantify the levels of fluorescence indicative of live/dead cell labelling under these various conditions, images were opened on Zeiss ZEN 3.1 blue edition software (Carl Zeiss Microscopy $\mathrm{GmbH}$, Munich, Germany) and the metatarsal area was manually traced. After tracing the area, the average fluorescence was obtained automatically by the software for both the FITC (live cells) and Texas Red (dead cells) channels. Graphs were then displayed by average fluorescence per $\mu \mathrm{m}^{2}$ to allow for direct comparison between metatarsi with different lengths.

\subsection{Confocal Imaging}

After 14 days in culture, metatarsi were collected in bijoux tubes and fixed in $10 \%$ neutral buffered formalin (NBF) for at least $24 \mathrm{~h}$ prior to clearing to facilitate 3D imaging of the entire immunochemically-labelled sample by confocal microscopy. Immunolabelling and clearing were developed based on methods published by Marr et al. [65]. Accordingly, metatarsi were processed according to Visikol ${ }^{\mathrm{TM}}$ guidelines, and all steps were performed with orbital agitation at 60 RPM. Metatarsi were taken from the fixative and washed with TBS, then permeabilized using three graded methanol dilutions in TBS or $\mathrm{dH}_{2} \mathrm{O}(50 \%$ $(v / v$ TBS $), 80 \%\left(v / v \mathrm{dH}_{2} \mathrm{O}\right)$, and $100 \%$ methanol) for a period of $1 \mathrm{~h}$ at $4{ }^{\circ} \mathrm{C}$. Thereafter, samples were washed with detergent $(0.2 \%$ Triton X-100) $(20 \% v / v)$ DMSO:methanol, 80\% methanol: $\mathrm{dH}_{2} \mathrm{O}, 50 \%$ methanol:TBS, $100 \%$ TBS and TBS:0.2\% Triton) for $3.5 \mathrm{~h}$ at $4{ }^{\circ} \mathrm{C}$, followed by pre-block penetration with TBS, Triton X-100, glycine and DMSO (SigmaAldrich, USA) for $1 \mathrm{~h}$ at RT. This was followed by blocking of samples in $6 \%$ donkey and $6 \%$ goat serum (in pre-block penetration solution) for $3 \mathrm{~h}$ at $37{ }^{\circ} \mathrm{C}$, and then incubation in anti-rabbit PCNA (1:50, Abcam, UK) primary antibody in TBS-Tween-20 $(0.2 \% v / v)$, $6 \%$ donkey serum, $6 \%$ goat serum and $5 \%$ DMSO at $37{ }^{\circ} \mathrm{C}$ overnight. Samples were then washed three times in TBS-Tween-20 $(0.2 \% v / v)$ for $1 \mathrm{~h}$ and then incubated in goat antirabbit Alexa Fluor 594 (1:500, Abcam, UK) secondary antibody in TBS-Tween-20 (0.2\% v/v) 
at $37^{\circ} \mathrm{C}$ for $8 \mathrm{~h}$. Incubation in secondary antibody was followed by another series of washes in TBS-Tween-20 $(0.2 \% \mathrm{v} / \mathrm{v})$ and the sample was finally incubated in $4^{\prime}, 6$-diamidino-2phenylindole (DAPI, dilution 1:2000, Sigma-Aldrich, Germany) overnight before a final set of washes at $37^{\circ} \mathrm{C}$, and dehydration in graded methanol dilutions. After immunolabelling, samples were cleared in HISTO- $1^{\mathrm{TM}}$ and HISTO-2 ${ }^{\mathrm{TM}}$ solutions (proprietor supplied) using the Visikol ${ }^{\circledR}$ kit and following the manufacturer's instructions. Briefly, metatarsi were immersed in HISTO- ${ }^{\mathrm{TM}}$ solution for $1 \mathrm{~h}$, followed by immersion in HISTO-2 ${ }^{\mathrm{TM}}$ solution for a minimum of $2 \mathrm{~h}$. Samples were stored in HISTO-2 ${ }^{\mathrm{TM}}$ prior to imaging.

Samples were transferred to a confocal imaging plate with a glass bottom in HISTO$2^{\mathrm{TM}}$ solution for imaging. Metatarsi were imaged on a Leica SP8 confocal microscope with a motorised stage (Leica Biosystems, Nussloch, Germany). Images were acquired with a 20x objective; pinhole size was set to 1 airy unit, line average was set to 48 , and electronic zoom was set to 1.70. Sequential scans of samples (approx. $228 \mu \mathrm{m} \times 228 \mu \mathrm{m} \times 241 \mu \mathrm{m}$ ) were captured using lasers emitting light at 405 (blue channel; DAPI) and 561 (red channel; Alexa Fluor 594) $\mathrm{nm}$ to detect fluorescence with a low laser power $(<10 \%)$, and $8000 \mathrm{~Hz}$ scanning speed. 3D analysis and visualisation were performed using Leica LAS-X v3.5.5 software (Leica Biosystems, Nussloch, Germany). To quantify the fluorescence under control and hydrogel-treated conditions, Leica image files (.lif) files were opened on Volocity software v6.3.0 (Quorum Technologies, Puslinch, Canada) and the metatarsal volume was traced using an intensity threshold to find all blue fluorescence (DAPI channel), then rejecting all but very large objects. Red fluorescence (PCNA channel) was obtained automatically after running the protocol for DAPI by re-using the same traced volume. Average fluorescence per $\mu \mathrm{m}^{3}$ is displayed to allow direct comparison of cell density labelling between metatarsi of divergent lengths.

\subsection{RNA Isolation}

At each specified endpoint, metatarsi were collected and pooled ( 2 bones) to allow for isolation of sufficient RNA $(\sim 15-20 \mathrm{ng} / \mu \mathrm{L})$; between $2-6$ replicate pooled samples were analysed per condition (representative of $n=4-12$ single bones). Accordingly, metatarsi were placed directly into a tube containing $200 \mu \mathrm{L}$ of RNA later ${ }^{\mathrm{TM}}$ stabilization solution (Invitrogen, Waltham, MA, USA) and stored at $-80^{\circ} \mathrm{C}$ until isolation. For RNA isolation, thawed metatarsals were transferred on ice to $1.5 \mathrm{~mL}$ RNAse-free tubes, containing $1 \mathrm{~mL}$ of QIAzol (Qiagen, Hilden, Germany) and manually homogenized by grinding with a plastic pestle. The homogenate was subsequently processed, and the RNA isolated using a RNeasy plus micro kit (Qiagen, Hilden, Germany), involving genomic DNA exclusion, chloroform incubation, RNA clean-up, membrane washing and mRNA elution (RNAse-free water).

\subsection{Multiplex Real Time Polymerase Chain Reaction}

Prior to multiplex RT-PCR, mRNA integrity and concentration were determined using RNA Nano chips on a 2100 Bioanalyzer Instrument (Agilent, Santa Clara, CA, USA) following the manufacturer's instructions. Samples with an RNA integrity number (RIN) $\geq 7$ and a concentration between $15-20 \mathrm{ng} / \mu \mathrm{L}$ were considered of suitable quantity and purity for analysis. Primers were designed based upon FASTA sequences and accession numbers obtained from the NCBI website for: Vegf, Sox9, Runx2, Alpl, Ihh, Tbsp4, Il6, Col10, Mmp13, Pthrp, Acan, Col2 and Akt and housekeeping genes Actb and Gapdh. Genes were selected as representative of early (Runx2, Acan, Col2, Ihh, Pthrp, Sox9) and late EO (Mmp13, Alpl, Vegf, Col10) or as were markers of mTOR (Akt) and NF-kB (Il6) pathway activation; Tsp4 was also included.

GenomeLab GeXP Genetic Analysis System (Sciex, Beckman and Coulter, Framingham, MA, USA) primer design tool was used to obtain the forward and reverse primer sequences (Table 3; Sigma-Aldrich, St. Louis, MO, USA). Primers were solubilised in RNAse/DNAse-free water and stored at $-20{ }^{\circ} \mathrm{C}$. Reverse transcriptase and PCR reactions were performed using GeXP protocols. Briefly, a primer master mix was prepared in two steps: a reverse transcription reaction and a forward PCR reaction. In the reverse 
transcription reaction, the stock concentrations of all the reverse primers were $100 \mu \mathrm{M}$ and the working concentration was $0.5 \mu \mathrm{M}$ (500 nM); in the forward PCR reaction, the stock concentration of all the forward primers was $100 \mu \mathrm{M}$ and the working concentration was $0.2 \mu \mathrm{M}(200 \mathrm{nM})$. RT reaction parameters: $48^{\circ} \mathrm{C}$ for $1 \mathrm{~min}, 42^{\circ} \mathrm{C}$ for $1 \mathrm{~h}, 95^{\circ} \mathrm{C}$ for $5 \mathrm{~min}$ and hold at $4{ }^{\circ} \mathrm{C}$. PCR reaction parameters: $95^{\circ} \mathrm{C}$ for $10 \mathrm{~min}, 94{ }^{\circ} \mathrm{C}$ for $30 \mathrm{~s}-55^{\circ} \mathrm{C}$ for $30 \mathrm{~s}-70{ }^{\circ} \mathrm{C}$ for $1 \mathrm{~min}$ and repeat for 35 cycles then hold at $10^{\circ} \mathrm{C}$. Raw data was obtained using GeXP software and the mRNA levels for Gapdh and $\beta$-actin $(A c t b)$ were obtained and results analysed using GraphPad Prism v9 (GraphPad Software Inc., San Diego, CA, USA). Data were normalised for both Gapdh and $\beta$-actin (Actb) housekeeping genes automatically using the GenomeLab GeXP Genetic Analysis System (Sciex, Beckman and Coulter, Framingham, MA, USA).

Table 3. List of primers used for multiplex RT-PCR.

\begin{tabular}{|c|c|c|}
\hline Gene & & Sequence $\left(5^{\prime}-3^{\prime}\right)$ \\
\hline \multirow{2}{*}{ Vegf } & $\mathrm{F}$ & AGGTGACACTATAGAATAGCTGTGTGTGTGAGTGGCTT \\
\hline & $\mathrm{R}$ & GTACGACTCACTATAGGGACTCTTTTCTCTGCCTCCGTG \\
\hline \multirow{2}{*}{ Sox9 } & $\mathrm{F}$ & AGGTGACACTATAGAATAAGGAAGCTGGCAGACCAGTA \\
\hline & $\mathrm{R}$ & GTACGACTCACTATAGGGACGTTCTTCACCGACTTCCTC \\
\hline \multirow{2}{*}{ Runx2 } & $\mathrm{F}$ & AGGTGACACTATAGAATAACAGTCCCAACTTCCTGTGC \\
\hline & $\mathrm{R}$ & GTACGACTCACTATAGGGATAGTTCTCATCATTCCCGGC \\
\hline \multirow{2}{*}{ Alpl } & $\mathrm{F}$ & AGGTGACACTATAGAATACACTCAAGGGAGAGGTCCAG \\
\hline & $\mathrm{R}$ & GTACGACTCACTATAGGGACCCAAGAGAGAAACCTGCTG \\
\hline \multirow{2}{*}{ Ihh } & $\mathrm{F}$ & AGGTGACACTATAGAATACCGAACCTTCATCTTGGTGT \\
\hline & $\mathrm{R}$ & GTACGACTCACTATAGGGACCCCGAGAAACATTGGAGTA \\
\hline \multirow{2}{*}{ Tbsp4 } & $\mathrm{F}$ & AGGTGACACTATAGAATATTCAGTCCCCAACTCCAAAC \\
\hline & $\mathrm{R}$ & GTACGACTCACTATAGGGACGTTTCCCGTGTAACCATCT \\
\hline \multirow{2}{*}{ Il6 } & $\mathrm{F}$ & AGGTGACACTATAGAATAAGTTGCCTTCTTGGGACTGA \\
\hline & $\mathrm{R}$ & GTACGACTCACTATAGGGAAGCCTCCGACTTGTGAAGTG \\
\hline \multirow{2}{*}{ Col10 } & $\mathrm{F}$ & AGGTGACACTATAGAATAGCAATTGCAGAAAGTCCACA \\
\hline & $\mathrm{R}$ & GTACGACTCACTATAGGGACTCGATTGAAAGGCACACAA \\
\hline \multirow{2}{*}{ Mmp13 } & $\mathrm{F}$ & AGGTGACACTATAGAATACCAGAACTTCCCAACCATGT \\
\hline & $\mathrm{R}$ & GTACGACTCACTATAGGGAGTCTTCCCCGTGTTCTCAAA \\
\hline \multirow{2}{*}{ Pthrp } & $\mathrm{F}$ & AGGTGACACTATAGAATATTCCTGCTCAGCTACTCCGT \\
\hline & $\mathrm{R}$ & GTACGACTCACTATAGGGAGGTAGCTCTGATTTCGGCTG \\
\hline \multirow{2}{*}{ Acan } & $\mathrm{F}$ & AGGTGACACTATAGAATAAGGACTGAAATCAGCGGAGA \\
\hline & $\mathrm{R}$ & GTACGACTCACTATAGGGATGTCTCTGTAGGGTACCGGG \\
\hline \multirow{2}{*}{ Col2 } & $\mathrm{F}$ & AGGTGACACTATAGAATAACACTGGTAAGTGGGGCAAG \\
\hline & $\mathrm{R}$ & GTACGACTCACTATAGGGATCGCAATGGATTGTGTTGTT \\
\hline \multirow{2}{*}{ Akt } & $\mathrm{F}$ & AGGTGACACTATAGAATAGCAGTGGACCACAGTCATTG \\
\hline & $\mathrm{R}$ & GTACGACTCACTATAGGGACATCGTCTCTTCTTCCTGCC \\
\hline \multirow{2}{*}{ Gapdh } & $\mathrm{F}$ & AGGTGACACTATAGAATAGGGTGTGAACCACGAGAAAT \\
\hline & $\mathrm{R}$ & GTACGACTCACTATAGGGAACTGTGGTCATGAGCCCTTC \\
\hline \multirow{2}{*}{ Actb } & $\mathrm{F}$ & AGGTGACACTATAGAATAGTACCACCATGTACCCAGGC \\
\hline & $\mathrm{R}$ & GTACGACTCACTATAGGGAGTACTTGCGCTCAGGAGGAG \\
\hline
\end{tabular}

\subsection{Assessment of mTOR and NF-kB Activity in Culture Supernatant}

To quantify the mTOR and NF-kB activity present in ex vivo cultures, enzyme-linked immunosorbent assays (ELISAs) were performed using medium conditioned by metatarsals. All metatarsal-conditioned supernatants were collected following 14 days and stored at $-80{ }^{\circ} \mathrm{C}$ until usage. IL-6 ELISA (Sigma-Aldrich, St. Louis, MO, USA) was used according to the manufacturer's instructions; IL-6 was selected as a readily accessible downstream 
read-out of NF-kB pathway activity. Assays were performed in duplicate for each sample using a Tecan Pro 200 plate reader (Tecan, Männedorf, Switzerland).

\subsection{Flow Cytometry}

Flow cytometric analysis was applied to metatarsi cultured for 5, 7 and 14 days under either control and hydrogel-treated conditions; entire metatarsi were digested with collagenase IV [66] and subsequently stained with propidium iodide (PI) before analysis using the methods described by Kim and Cecchini $[67,68]$. Metatarsals were collected (4 to 10 pooled/sample) for enzyme digestion, which involved transferral to FACS tubes containing $1 \mathrm{~mL}$ of fresh culture medium (see [17]) supplemented with $86.5 \mathrm{U} / \mathrm{mL}$ collagenase IV (Worthington Biochem, Lakewood, NJ, USA) and $10 \mu \mathrm{L} / \mathrm{mL}$ of DNAse A (Invitrogen, USA), prior to incubation at $37^{\circ} \mathrm{C} / 5 \% \mathrm{CO}_{2}$ and mixing by inversion every $15 \mathrm{~min}$ for $4 \mathrm{~h}$. These samples were then centrifuged for $5 \mathrm{~min}$ at $300 \times g$ and the cell supernatant washed with fresh medium and then filtered (70 $\mu \mathrm{m}$ cell strainer) before re-centrifugation. Each cell suspension aliquot was then fixed by resuspension in ice-cold $70 \%$ ethanol for $30 \mathrm{~min}$ before another round of centrifugation and subsequent washing in ice-cold PBS (Gibco, Waltham, MA, USA) containing 0.2\% BSA (Sigma-Aldrich, USA). Tubes were stored in the dark at $4{ }^{\circ} \mathrm{C}$ until staining.

For PI staining, cells were centrifuged for $5 \mathrm{~min}$ at $300 \times g$ (without active braking) and $900 \mu \mathrm{L}$ of PBS $/ 0.2 \%$ BSA was taken from each tube and $500 \mu \mathrm{L}$ of staining solution containing $10 \mu \mathrm{g}$ PI (Thermofisher Scientific, Waltham, MA, USA), $5 \mu \mathrm{g}$ bovine RNAse A (Abcam, USA), 20\% triton X-100 and PBS/0.2\% BSA was added to each tube, and dye was incubated for $1 \mathrm{~h}$ at RT protected from light. After another round of centrifugation and two washes in PBS $/ 0.2 \%$ BSA, $900 \mu \mathrm{L}$ of PBS $/ 0.2 \%$ BSA was added, and tubes were finally kept at $4{ }^{\circ} \mathrm{C}$, protected from light until the flow cytometry. Cells were processed using a BD FACSCanto II Flow Cytometer (BD Biosciences, USA) and appropriate gating was applied to the expected PI pattern (30,000 events) on FlowJo v10.7.0 software (BD, Franklin Lanes, NJ, USA).

\subsection{Statistical Analysis}

Analyses of pooled data were performed using a linear mixed effect model in R v3.6.1 (R Foundation for Statistical Computing, Auckland, New Zealand) and RStudio v1.2.5019 (RStudio Inc., Boston, MA, USA) using xlsx, lattice, latticeExtra, lme4, lmerTest and phia packages and graphs were generated on GraphPad Prism 9 (GraphPad Software Inc., San Diego, CA, USA). Data are presented in intervals that represent the mean and SD. According to the normality test distribution, two variable comparison t-tests or Mann-Whitney tests were used. For more than two variables, one-way ANOVA was used. $p$ values lower than 0.05 were considered statistically significant throughout.

\section{Conclusions}

The studies described here revealed the sensitivity of the interaction between the mTOR pathway and mechanics, with an inhibitor (rapamycin) and an activator (leucine) of mTOR both effectively reversing the arrest in growth exerted by hydrogel-mediated quasi static loading. mTOR is described for the first time as being a pathway with a bidirectional feedback capacity in the control of endochondral growth, as it seems to compensate for inhibition in one its complexes (mTORC1) by maintaining the other (mTORC2, and viceversa; Figure 5). 


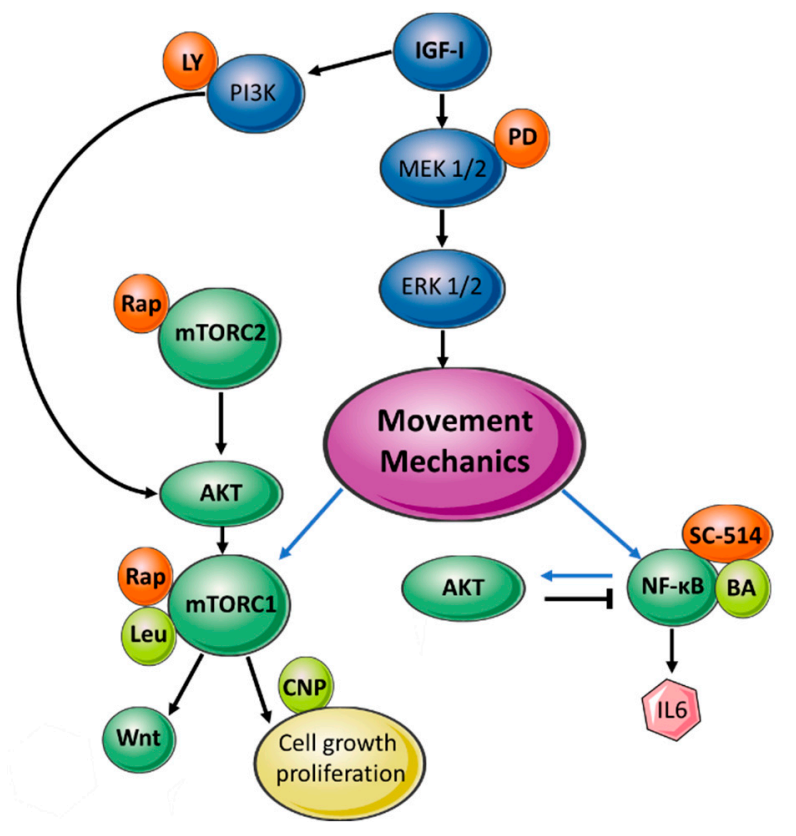

Figure 5. Summary of NF-kB/mTOR and interaction with mechanics. Dark green circlespathway factors; yellow circles-external factors; light green circles-activator compound; orange circles-inhibitor compound; blue circles-IGF-I pathway; purple circles-movement/loading; pink hexagon-readout markers; black arrows_interactions between mTOR, NF-kB and AKT; blue arrows — effects of quasi-static loading. BA—betulinic acid; Rap—rapamycin; Leu—leucine; PD— PD98059; LY-LY294002; CNP-C-type natriuretic peptide.

Author Contributions: Conceptualization, S.C.-S. and A.A.P.; methodology, S.C.-S., B.H.S., N.M., A.H. and S.P.A.; formal analysis, S.C.-S.; writing-original draft preparation S.C.-S. and A.A.P.; writing-review and editing S.C.-S. and A.A.P.; supervision, S.P.A. and A.A.P.; All authors have read and agreed to the published version of the manuscript.

Funding: This research was funded by the European Union's Horizon 2020 research and innovation programme under Marie Sklodowska-Curie grant agreement No 721432. A.A.P. was also a recipient during this period of support from EPSRC, Osteoarthritis Technology Network Plus: a multidisciplinary approach to the prevention and treatment of osteoarthritis EP/N027264/1.

Institutional Review Board Statement: All animal procedures were performed in accordance with the Home Office guidelines in the UK, the Animals (Scientific Procedures) Act 1986, under PPLs 70/7859 and P253385BB2, and PIL I5FB864C0 and were approved by the Royal Veterinary College's ethics committee.

Informed Consent Statement: Not applicable.

Data Availability Statement: Not applicable.

Acknowledgments: Charlotte Lawson and Randy Ballesteros for the flow cytometry training and results discussion and Ruby (Yu-Mei) Chang for their help with the statistical analysis.

Conflicts of Interest: The authors declare no conflict of interest.

\section{References}

1. Huang, W.; Chung, U.-I.; Kronenberg, H.M.; de Crombrugghe, B. The chondrogenic transcription factor Sox9 is a target of signaling by the parathyroid hormone-related peptide in the growth plate of endochondral bones. Proc. Natl. Acad. Sci. USA 2001, 98, 160-165. [CrossRef]

2. Shu, B.; Zhang, M.; Xie, R.; Wang, M.; Jin, H.; Hou, W.; Tang, D.; Harris, S.E.; Mishina, Y.; O’Keefe, R.J.; et al. BMP2, but not BMP4, is crucial for chondrocyte proliferation and maturation during endochondral bone development. J. Cell Sci. 2011, 124, 3428-3440. [CrossRef] 
3. Hutchison, M.R.; Bassett, M.H.; White, P.C. Insulin-like growth factor-I and fibroblast growth factor, but not growth hormone, affect growth plate chondrocyte proliferation. Endocrinology 2007, 148, 3122-3130. [CrossRef]

4. Provot, S.; Schipani, E. Molecular mechanisms of endochondral bone development. Biochem. Biophys. Res. Commun. 2005, 328, 658-665. [CrossRef] [PubMed]

5. Mackie, E.J.; Ahmed, Y.A.; Tatarczuch, L.; Chen, K.S.; Mirams, M. Endochondral ossification: How cartilage is converted into bone in the developing skeleton. Int. J. Biochem. Cell Biol. 2008, 40, 46-62. [CrossRef] [PubMed]

6. White, A.; Wallis, G. Endochondral ossification: A delicate balance between growth and mineralisation. Curr. Biology. 2001, 11, R589-R591. [CrossRef]

7. Gerber, H.P.; Vu, T.H.; Ryan, A.M.; Kowalski, J.; Werb, Z.; Ferrara, N. VEGF couples hypertrophic cartilage remodeling, ossification and angiogenesis during endochondral bone formation. Nat. Med. 1999, 5, 623-628. [CrossRef]

8. Haeusler, G.; Walter, I.; Helmreich, M.; Egerbacher, M. Localization of matrix metalloproteinases, (MMPs) their tissue inhibitors, and vascular endothelial growth factor (VEGF) in growth plates of children and adolescents indicates a role for MMPs in human postnatal growth and skeletal maturation. Calcif. Tissue Int. 2005, 76, 326-335. [CrossRef] [PubMed]

9. Zimmermann, E.A.; Bouguerra, S.; Londono, I.; Moldovan, F.; Aubin, C.E.; Villemure, I. In situ deformation of growth plate chondrocytes in stress-controlled static vs. dynamic compression. J. Biomech. 2017, 56, 76-82. [CrossRef]

10. Carroll, S.F.; Buckley, C.T.; Kelly, D.J. Cyclic Tensile Strain Can Play a Role in Directing both Intramembranous and Endochondral Ossification of Mesenchymal Stem Cells. Front Bioeng. Biotechnol. 2017, 5, 73. [CrossRef] [PubMed]

11. Miyamoto, S.; Yoshikawa, H.; Nakata, K. Axial mechanical loading to ex vivo mouse long bone regulates endochondral ossification and endosteal mineralization through activation of the BMP-Smad pathway during postnatal growth. Bone Rep. 2021, 15, 101088. [CrossRef]

12. Nowlan, N.C.; Sharpe, J.; Roddy, K.A.; Prendergast, P.J.; Murphy, P. Mechanobiology of embryonic skeletal development: Insights from animal models. Birth Defects Res. Part C Embryo Today Rev. 2010, 90, 203-213. [CrossRef]

13. Roddy, K.A.; Prendergast, P.J.; Murphy, P. Mechanical influences on morphogenesis of the knee joint revealed through morphological, molecular and computational analysis of immobilised embryos. PLoS ONE 2011, 6, e17526. [CrossRef]

14. Shea, C.A.; Rolfe, R.A.; Murphy, P. The importance of foetal movement for co-ordinated cartilage and bone development in utero. Bone Jt. Res. 2015, 4, 105-116. [CrossRef]

15. Levillain, A.; Rolfe, R.A.; Huang, Y.; Iatridis, J.C.; Nowlan, N.C. Short-term foetal immobility temporally and progressively affects chick spinal curvature and anatomy and rib development. Eur. Cells Mater. 2019, 37, 23-41. [CrossRef] [PubMed]

16. Rolfe, R.A.; O'Callaghan, D.S.; Murphy, P. Joint development recovery on resumption of embryonic movement following paralysis. Dis. Models Mech. 2021, 14, dmm048913. [CrossRef]

17. Houston, D.A.; Staines, K.A.; MacRae, V.E.; Farquharson, C. Culture of Murine Embryonic Metatarsals: A Physiological Model of Endochondral Ossification. J. Vis. Exp. 2016, 118, e54978. [CrossRef] [PubMed]

18. Marino, S.; Staines, K.A.; Brown, G.; Howard-Jones, R.A.; Adamczyk, M. Models of ex vivo explant cultures: Applications in bone research. Bonekey Rep. 2016, 5, 818. [CrossRef] [PubMed]

19. Dobie, R.; Ahmed, S.F.; Staines, K.A.; Pass, C.; Jasim, S.; MacRae, V.E.; Farquharson, C. Increased linear bone growth by GH in the absence of SOCS2 is independent of IGF-1. J. Cell. Physiol. 2015, 230, 2796-2806. [CrossRef]

20. Macrae, V.E.; Ahmed, S.F.; Mushtaq, T.; Farquharson, C. IGF-I signalling in bone growth: Inhibitory actions of dexamethasone and IL-1beta. Growth Horm. IGF Res. 2007, 17, 435-439. [CrossRef] [PubMed]

21. Rokutanda, S.; Fujita, T.; Kanatani, N.; Yoshida, C.A.; Komori, H.; Liu, W.; Mizuno, A.; Komori, T. Akt regulates skeletal development through GSK3, mTOR, and FoxOs. Dev. Biol. 2009, 328, 78-93. [CrossRef] [PubMed]

22. Hahn-Windgassen, A.; Nogueira, V.; Chen, C.C.; Skeen, J.E.; Sonenberg, N.; Hay, N. Akt activates the mammalian target of rapamycin by regulating cellular ATP level and AMPK activity. J. Biol. Chem. 2005, 280, 32081-32089. [CrossRef] [PubMed]

23. Dan, H.C.; Ebbs, A.; Pasparakis, M.; Van Dyke, T.; Basseres, D.S.; Baldwin, A.S. Akt-dependent activation of mTORC1 complex involves phosphorylation of mTOR (mammalian target of rapamycin) by IkappaB kinase alpha (IKKalpha). J. Biol. Chem. 2014, 289, 25227-25240. [CrossRef]

24. Sun, K.; Luo, J.; Guo, J.; Yao, X.; Jing, X.; Guo, F. The PI3K/AKT/mTOR signaling pathway in osteoarthritis: A narrative review. Osteoarthr. Cartil. 2020, 28, 400-409. [CrossRef] [PubMed]

25. Pollard, A.S.; Charlton, B.G.; Hutchinson, J.R.; Gustafsson, T.; McGonnell, I.M.; Timmons, J.A.; Pitsillides, A.A. Limb proportions show developmental plasticity in response to embryo movement. Sci. Rep. 2017, 7, 41926. [CrossRef]

26. Rawlinson, S.C.; Murray, D.H.; Mosley, J.R.; Wright, C.D.; Bredl, J.C.; Saxon, L.K.; Loveridge, N.; Leterrier, C.; Constantin, P.; Farquharson, C.; et al. Genetic selection for fast growth generates bone architecture characterised by enhanced periosteal expansion and limited consolidation of the cortices but a diminution in the early responses to mechanical loading. Bone 2009, 45, 357-366. [CrossRef] [PubMed]

27. Guan, Y.; Yang, X.; Yang, W.; Charbonneau, C.; Chen, Q. Mechanical activation of mammalian target of rapamycin pathway is required for cartilage development. FASEB J. 2014, 28, 4470-4481. [CrossRef]

28. Fitter, S.; Matthews, M.P.; Martin, S.K.; Xie, J.; Ooi, S.S.; Walkley, C.R.; Codrington, J.D.; Ruegg, M.A.; Hall, M.N.; Proud, C.G.; et al. mTORC1 Plays an Important Role in Skeletal Development by Controlling Preosteoblast Differentiation. Mol. Cell. Biol. 2017, 37, e00668-16. [CrossRef]

29. Chen, J.; Long, F. mTOR signaling in skeletal development and disease. Bone Res. 2018, 6, 1. [CrossRef] 
30. Agirdil, Y. The growth plate: A physiologic overview. EFORT Open Rev. 2020, 5, 498-507. [CrossRef]

31. Novack, D.V. Role of NF-kappaB in the skeleton. Cell Res. 2011, 21, 169-182. [CrossRef] [PubMed]

32. Jimi, E.; Fei, H.; Nakatomi, C. NF-kappaB Signaling Regulates Physiological and Pathological Chondrogenesis. Int. J. Mol. Sci. 2019, 20, 6275. [CrossRef] [PubMed]

33. Alvarez, J.; Sohn, P.; Zeng, X.; Doetschman, T.; Robbins, D.J.; Serra, R. TGFb2 mediates the effects of Hedgehog on hypertrophic differentiation and PTHrP expression. Development 2002, 129, 1913-1924. [CrossRef]

34. Amano, K.; Ichida, F.; Sugita, A.; Hata, K.; Wada, M.; Takigawa, Y.; Nakanishi, M.; Kogo, M.; Nishimura, R.; Yoneda, T. MSX2 stimulates chondrocyte maturation by controlling Ihh expression. J. Biol. Chem. 2008, 283, 29513-29521. [CrossRef]

35. Huesa, C.; Houston, D.; Kiffer-Moreira, T.; Yadav, M.M.; Millan, J.L.; Farquharson, C. The Functional co-operativity of TissueNonspecific Alkaline Phosphatase (TNAP) and PHOSPHO1 during initiation of Skeletal Mineralization. Biochem. Biophys. Rep. 2015, 4, 196-201. [CrossRef]

36. Cai, H.; Liu, A. Spop promotes skeletal development and homeostasis by positively regulating Ihh signaling. Proc. Natl. Acad. Sci. USA 2016, 113, 14751-14756. [CrossRef] [PubMed]

37. Kurki, P.; Vanderlaan, M.; Dolbeare, F.; Gray, J.; Tan, E.M. Expression of proliferating cell nuclear antigen (PCNA)/cyclin during the cell cycle. Exp. Cell Res. 1986, 166, 209-219. [CrossRef]

38. Ohashi, N.; Robling, A.G.; Burr, D.B.; Turner, C.H. The effects of dynamic axial loading on the rat growth plate. J. Bone Miner. Res. 2002, 17, 284-292. [CrossRef]

39. Benoit, A.; Mustafy, T.; Londono, I.; Grimard, G.; Aubin, E.; Villemure, I. In vivo dynamic compression has less detrimental effect than static compression on newly formed bone of a rat caudal vertebra. J. Musculoskelet Neuronal Interact. 2016, 16, 211-220.

40. Ferrao Blanco, M.N.; Bastiaansen-Jenniskens, Y.M.; Chambers, M.G.; Pitsillides, A.A.; Narcisi, R.; van Osch, G. Effect of Inflammatory Signaling on Human Articular Chondrocyte Hypertrophy: Potential Involvement of Tissue Repair Macrophages. Cartilage 2021, 19476035211021907. [CrossRef]

41. Marcu, K.B.; Otero, M.; Olivotto, E.; Borzi, R.M.; Goldring, M.B. NF-кB Signaling: Multiple angles to target OA. Curr. Drug Targets 2010, 11, 599-613. [CrossRef] [PubMed]

42. Chang, J.; Wang, Z.; Tang, E.; Fan, Z.; McCauley, L.; Franceschi, R.; Guan, K.; Krebsbach, P.H.; Wang, C.Y. Inhibition of osteoblastic bone formation by nuclear factor-kappaB. Nat. Med. 2009, 15, 682-689. [CrossRef] [PubMed]

43. Liu, Q.; Wu, H.; Chim, S.M.; Zhou, L.; Zhao, J.; Feng, H.; Wei, Q.; Wang, Q.; Zheng, M.H.; Tan, R.X.; et al. SC-514, a selective inhibitor of IKKbeta attenuates RANKL-induced osteoclastogenesis and NF-kappaB activation. Biochem. Pharmacol. 2013, 86, 1775-1783. [CrossRef] [PubMed]

44. Son, S.M.; Park, S.J.; Lee, H.; Siddiqi, F.; Lee, J.E.; Menzies, F.M.; Rubinsztein, D.C. Leucine Signals to mTORC1 via Its Metabolite Acetyl-Coenzyme A. Cell Metab. 2019, 29, 192-201. [CrossRef]

45. Condon, K.J.; Sabatini, D.M. Nutrient regulation of mTORC1 at a glance. J. Cell Sci. 2019, 132, jcs222570. [CrossRef]

46. Kasperczyk, H.; La Ferla-Bruhl, K.; Westhoff, M.A.; Behrend, L.; Zwacka, R.M.; Debatin, K.M.; Fulda, S. Betulinic acid as new activator of NF-kappaB: Molecular mechanisms and implications for cancer therapy. Oncogene 2005, 24, 6945-6956. [CrossRef]

47. Kroemer, S.F.A.G. Targeting mitochondrial apoptosis by betulinic acid in human cancers. Drug Discov. Today 2009, 14, 885-890. [CrossRef]

48. Liu, V.W.S.; Yau, W.L.; Tam, C.W.; Yao, K.M.; Shiu, S.Y.W. Melatonin Inhibits Androgen Receptor Splice Variant-7 (AR-V7)-Induced Nuclear Factor-Kappa B (NF-kB) Activation and NF-kB Activator-Induced AR-V7 Expression in Prostate Cancer Cells: Potential Implications for the Use of Melatonin in Castration-Resistant Prostate Cancer (CRPC) Therapy. Int. J. Mol. Sci. 2017, 18, 1130. [CrossRef]

49. Choi, H.; Jeong, B.C.; Kook, M.S.; Koh, J.T. Betulinic acid synergically enhances BMP2-induced bone formation via stimulating Smad 1/5/8 and p38 pathways. J. Biomed. Sci. 2016, 23, 45. [CrossRef]

50. Jeong, D.H.; Kwak, S.C.; Lee, M.S.; Yoon, K.H.; Kim, J.Y.; Lee, C.H. Betulinic Acid Inhibits RANKL-Induced Osteoclastogenesis via Attenuating Akt, NF-kappaB, and PLCgamma2-Ca(2+) Signaling and Prevents Inflammatory Bone Loss. J. Nat. Prod. 2020, 83, 1174-1182. [CrossRef]

51. Bachmann, B.; Spitz, S.; Schadl, B.; Teuschl, A.H.; Redl, H.; Nurnberger, S.; Ertl, P. Stiffness Matters: Fine-Tuned Hydrogel Elasticity Alters Chondrogenic Redifferentiation. Front Bioeng. Biotechnol. 2020, 8, 373. [CrossRef]

52. Sarrigiannidis, S.O.; Rey, J.M.; Dobre, O.; Gonzalez-Garcia, C.; Dalby, M.J.; Salmeron-Sanchez, M. A tough act to follow: Collagen hydrogel modifications to improve mechanical and growth factor loading capabilities. Mater. Today Bio 2021, $10,100098$. [CrossRef]

53. Hagel, V.; Haraszti, T.; Boehm, H. Diffusion and interaction in PEG-DA hydrogels. Biointerphases 2013, 8, 36. [CrossRef]

54. Figueiredo, L.; Pace, R.; D'Arros, C.; Rethore, G.; Guicheux, J.; Le Visage, C.; Weiss, P. Assessing glucose and oxygen diffusion in hydrogels for the rational design of 3D stem cell scaffolds in regenerative medicine. J. Tissue Eng. Regen. Med. 2018, 12, 1238-1246. [CrossRef]

55. Nam, J.; Aguda, B.D.; Rath, B.; Agarwal, S. Biomechanical thresholds regulate inflammation through the NF-kappaB pathway: Experiments and modeling. PLoS ONE 2009, 4, e5262. [CrossRef]

56. Segurado, M.; Tercero, J.A. The S-phase checkpoint: Targeting the replication fork. Biol. Cell 2009, 101, 617-627. [CrossRef]

57. Oeckinghaus, A.; Ghosh, S. The NF-kappaB family of transcription factors and its regulation. Cold Spring Harb. Perspect. Biol. 2009, 1, a000034. [CrossRef] 
58. Bloom, M.J.; Saksena, S.D.; Swain, G.P.; Behar, M.S.; Yankeelov, T.E.; Sorace, A.G. The effects of IKK-beta inhibition on early NF-kappa-B activation and transcription of downstream genes. Cell. Signal. 2019, 55, 17-25. [CrossRef]

59. Altaf, H.; Revell, P.A. Evidence for active antigen presentation by monocyte/macrophages in response to stimulation with particles: The expression of NFkappaB transcription factors and costimulatory molecules. Inflammopharmacology 2013, 21, 279-290. [CrossRef]

60. Kishore, N.; Sommers, C.; Mathialagan, S.; Guzova, J.; Yao, M.; Hauser, S.; Huynh, K.; Bonar, S.; Mielke, C.; Albee, L.; et al. A selective IKK-2 inhibitor blocks NF-kappa B-dependent gene expression in interleukin-1 beta-stimulated synovial fibroblasts. J. Biol. Chem. 2003, 278, 32861-32871. [CrossRef]

61. Jingbo, W.; Aimin, C.; Qi, W.; Xin, L.; Huaining, L. Betulinic acid inhibits IL-1beta-induced inflammation by activating PPARgamma in human osteoarthritis chondrocytes. Int. Immunopharmacol. 2015, 29, 687-692. [CrossRef]

62. Liu, C.; Chen, Y.; Lu, C.; Chen, H.; Deng, J.; Yan, Y.; Xu, Y.Y.; Liu, H.; Huang, H.; Wei, J.; et al. Betulinic acid suppresses Th17 response and ameliorates psoriasis-like murine skin inflammation. Int. Immunopharmacol. 2019, 73, 343-352. [CrossRef]

63. Li, Z.; Yang, Z.; Passaniti, A.; Lapidus, R.G.; Liu, X.; Cullen, K.J.; Dan, H.C. A positive feedback loop involving EGFR/Akt/mTORC1 and IKK/NF-kB regulates head and neck squamous cell carcinoma proliferation. Oncotarget 2016, 7, 31892-31906. [CrossRef]

64. Dan, H.C.; Antonia, R.J.; Baldwin, A.S. PI3K/Akt promotes feedforward mTORC2 activation through IKKalpha. Oncotarget 2016, 7, 21064-21075. [CrossRef] [PubMed]

65. Marr, N.; Hopkinson, M.; Hibbert, A.P.; Pitsillides, A.A.; Thorpe, C.T. Bimodal Whole-Mount Imaging of Tendon Using Confocal Microscopy and X-ray Micro-Computed Tomography. Biol. Proced. Online 2020, 22, 13. [CrossRef]

66. June, R.K.; Fyhrie, D.P. Enzymatic digestion of articular cartilage results in viscoelasticity changes that are consistent with polymer dynamics mechanisms. Biomed. Eng. Online 2009, 8, 32. [CrossRef]

67. Kim, K.H.; Sederstrom, J.M. Assaying Cell Cycle Status Using Flow Cytometry. Curr. Protoc. Mol. Biol. 2015, 111, 28.6.1-28.6.11. [CrossRef] [PubMed]

68. Cecchini, M.J.; Amiri, M.; Dick, F.A. Analysis of cell cycle position in mammalian cells. J. Vis. Exp. 2012, 59, 3491. [CrossRef] [PubMed] 